\title{
Evidence to Inform Occupational Therapy Intervention With Adults With Intellectual Disability: A Scoping Review
}

\author{
Meghan G. Blaskowitz, Khalilah R. Johnson, Theodore Bergfelt, Wanda J. Mahoney
}

Importance: Occupational therapy practitioners use a range of habilitative and compensatory approaches to teach new skills or modify tasks and environments to address occupational performance among adults with intellectual disability (ID); therefore, they must identify and use available evidence to guide intervention planning.

Objective: To summarize the scope of evidence that can inform occupational therapy intervention with adults with primary or comorbid ID.

Data Sources: Articles published in peer-reviewed journals between January 2002 and January 2018 and indexed in PubMed, CINAHL, PsycINFO, and Scopus.

Study Selection and Data Collection: A total of 159 articles met inclusion criteria and contained information on occupational therapy intervention with adults ages $18 \mathrm{yr}$ or older with primary or coexisting ID.

Findings: Fifty-seven of the 159 articles focused on intervention to address occupational performance outcomes (i.e., employment, self-care, leisure and social interaction, community participation).

Conclusions and Relevance: A wide range of literature is available to support occupational therapy intervention with adults with ID. Occupational therapy practitioners may be less knowledgeable about this evidence because much of it is located in non-occupational therapy or international journals.

What This Article Adds: This scoping review provides occupational therapy practitioners with evidence to support high-quality occupational therapy intervention with adults with ID.

\footnotetext{
0
} ccupational therapy practitioners support people with intellectual disability (ID) across their lifespan and in various practice settings, but the profession must do more to meet the specialized needs of this underserved population (Johnson et al., 2019). ID is a chronic condition diagnosed before age $18 \mathrm{yr}$ that significantly affects a person's intellectual and cognitive functioning as well as adaptive behavior skills, or the "conceptual, social, and practical skills [that people use to function] in their everyday lives" (American Association on Intellectual and Developmental Disabilities, n.d., Adaptive Behavior section, para. 1). ID is one type of developmental disability that often co-occurs with other developmental disabilities, such as cerebral palsy or autism spectrum disorder (ASD).

The demand for occupational therapy services has grown as the population of adults with ID has increased, postsecondary education and employment programs have expanded, and more people have transitioned from institutional to community settings (Berg et al., 2017; Dean et al., 2015). The inclusion of occupational therapy as a habilitative service under the essential health benefits of the Patient Protection and Affordable Care Act of 2010 (Public Law 111-148) has also increased demand for occupational therapy services, but greater advocacy, informed by evidence, may be needed for adults with ID to access these services (Brown, 2014).

Occupational therapy practitioners can play an integral role in supporting adults with ID in adaptive behavior skills through teaching, remediating, or adapting the activities of daily living (ADLs), instrumental activities of daily living 
(IADLs), and vocational and social activities essential to live meaningful lives (Johnson et al., 2019). Occupational therapy practitioners use habilitative (i.e., establish) and compensatory approaches to teach new skills or modify tasks and environments to maintain, enhance, or improve occupational performance among adults with ID (American Occupational Therapy Association [AOTA], 2014; Brown, 2014). To ensure the most effective and efficient care to improve occupational outcomes, occupational therapy practitioners need to use literature to inform ethical, evidencebased intervention with adults with ID.

Systematic and scoping reviews on occupational therapy practice with adults with intellectual and developmental disabilities (IDDs) exist in the literature; however, they have largely focused on occupational therapy intervention literature related to people with ASD or specific occupational performance issues (e.g., Harmuth et al., 2018; Williamson et al., 2017). Williamson et al. (2017) concentrated on describing literature on health care access and health management occupations of adults with ID. Reviews by Waldman-Levi et al. (2019) and Bathje et al. (2018) scoped the literature for interventions that aimed to enhance the occupational performance of adults with IDDs. However, Waldman-Levi et al. focused solely on ADL and IADL interventions with adolescents and adults with ID. Bathje et al.'s systematic review identified occupation-based intervention studies for adults with mild to moderate neurodevelopmental disorders, which limited their review to only 10 articles. This scoping review differs from previous reviews in its inclusion of literature on any occupational therapy-related intervention with adults with any level of ID.

It is imperative that occupational therapy practitioners identify the extent of literature available to guide intervention planning with this population. The purpose of this scoping review was to summarize literature that can inform occupational therapy intervention with adults with ID and categorize this evidence by occupational performance outcomes informed by the Occupational Therapy Practice Framework: Domain and Process (3rd ed.; OTPF-3; AOTA, 2014).

\section{Scoping Review: A Methodological Framework}

We used scoping review procedures as outlined by Arksey and O'Malley (2005). We completed the steps in a reflexive and iterative manner to ensure that the review was structured and thorough (Arksey \& O'Malley, 2005).

\section{Develop a Guiding Research Question}

After completing an exploratory search with broad search terms and discussing the preliminary results with the consulting university librarian with expertise in systematic and scoping reviews, we formulated the following research question: What is the scope of the evidence related to occupational therapy practice with adults with ID? We defined the relevance to occupational therapy practice through consensus discussions on the basis of the OTPF-3 and our

clinical experience with adults with ID. Because the scope of the literature was much broader than initially anticipated, this scoping review focuses on the following subquestion: What is the scope of the evidence related to occupational therapy intervention with adults with ID?

\section{Identify Relevant Literature}

We determined appropriate key words, and the consulting librarian constructed a custom search in PubMed, CINAHL, PsycINFO, and Scopus because these databases cover IDDs in scholarly journals across all disciplines. The custom search was not limited to occupational therapy journals to capture articles for which occupational therapy scholars were authors or coauthors that dealt with occupational therapy-related topics but were not necessarily published in occupational therapy-specific journals. A list of controlled vocabulary terms used in each database is provided in Table A.1 in the Appendix. Citations and abstracts from these searches were exported to EndNote (Clarivate Analytics, Philadelphia, PA) and uploaded into Covidence (https://www.covidence.org/), a web-based review management system. 


\section{Select Studies}

Articles were included for review if they (1) were published in English between January 2002 and January 2018, (2) were published in a peer-reviewed journal, (3) included content about people ages $18 \mathrm{yr}$ or older with primary or coexisting ID at any level, and (4) included information relevant to occupational therapy practice (e.g., related to occupational performance strengths and needs of people with ID). Articles were excluded if they (1) were literary criticism (e.g., book reviews, editorials) or conference proceedings; (2) were gray literature (e.g., dissertations, government reports); or (3) included only participants with physical, developmental, or cognitive disabilities without ID (e.g., adult-onset muscular dystrophy, high-functioning ASD, dementia). To establish reliability, three authors independently screened 20 titles and abstracts for inclusion, compared their decisions, discussed their reasoning, and came to consensus, documenting any clarification regarding inclusion and exclusion criteria. These authors conducted this reliability consensus of 20 articles three times until they reached $90 \%$ consistency.

\section{Map the Data}

We identified 3,402 articles for screening (1,203 PsycINFO; 1,102 CINAHL; 732 Scopus; and 365 PubMed). A total of 826 duplicates were removed, resulting in 2,576 articles to be screened. After reviewing titles and abstracts, we deemed 2,007 articles irrelevant to the research question, leaving 569 articles to be assessed for inclusion. Two authors conducted full-text screenings of each article, and three authors discussed and came to consensus regarding any disagreements about inclusion to ensure reliability. Of the 569 articles assessed, 410 were excluded, leaving 159 that met the inclusion criteria (Figure 1).

To analyze the full text of included articles, we extracted key information (e.g., purpose of the study, sample characteristics, types of evidence provided, areas of occupation addressed, measures used, implications for intervention) from each article into a shared Excel (Microsoft Corp., Redmond, WA) spreadsheet. For each article, one author completed the initial data extraction, and a second author reviewed and added to this information. The articles were divided into three major categories on the basis of the type of evidence that the article provided: descriptive, assessment, or intervention.

\section{Evaluate and Summarize Findings}

To develop codes for the 57 intervention articles, three authors independently reviewed extracted data, proposed inductive codes and descriptions, and deliberated initial codes. These authors reviewed the extracted data and referred to the full articles until they reached consensus about the coding structure, which developed into intervention outcome categories and intervention strategy categories. Subsequently, these authors assigned each article outcome and strategy codes, as appropriate, and used a shared audit trail to track individual coding. These authors also discussed differences in coding and referred back to full-text articles until reaching consensus.

\section{Results}

Of the 159 articles that met the inclusion criteria for the larger scoping review, data were extracted from 57 articles that provided intervention evidence. Articles were published in journals that were not occupational therapy specific (66\%), for example, Research in Developmental Disabilities, more frequently than in occupational therapy journals (34\%). Intervention evidence for adults with ID was international, with authors and research from 14 countries. The most frequently represented countries were the United Kingdom (26\%) and the United States (24\%). Half of the articles used small sample designs, including case studies (16 articles) or single-subject designs (13 articles).

Findings from the analyses of intervention articles depicted the intended outcomes of the intervention and intervention strategies (citations and summaries for all articles included in this scoping review can be found in Table A.2). The occupational therapy-related intervention outcomes highlighted in the literature included ADLs, employment, 
Figure 1. Flow diagram for inclusion and exclusion of peer-reviewed studies in the scoping review.
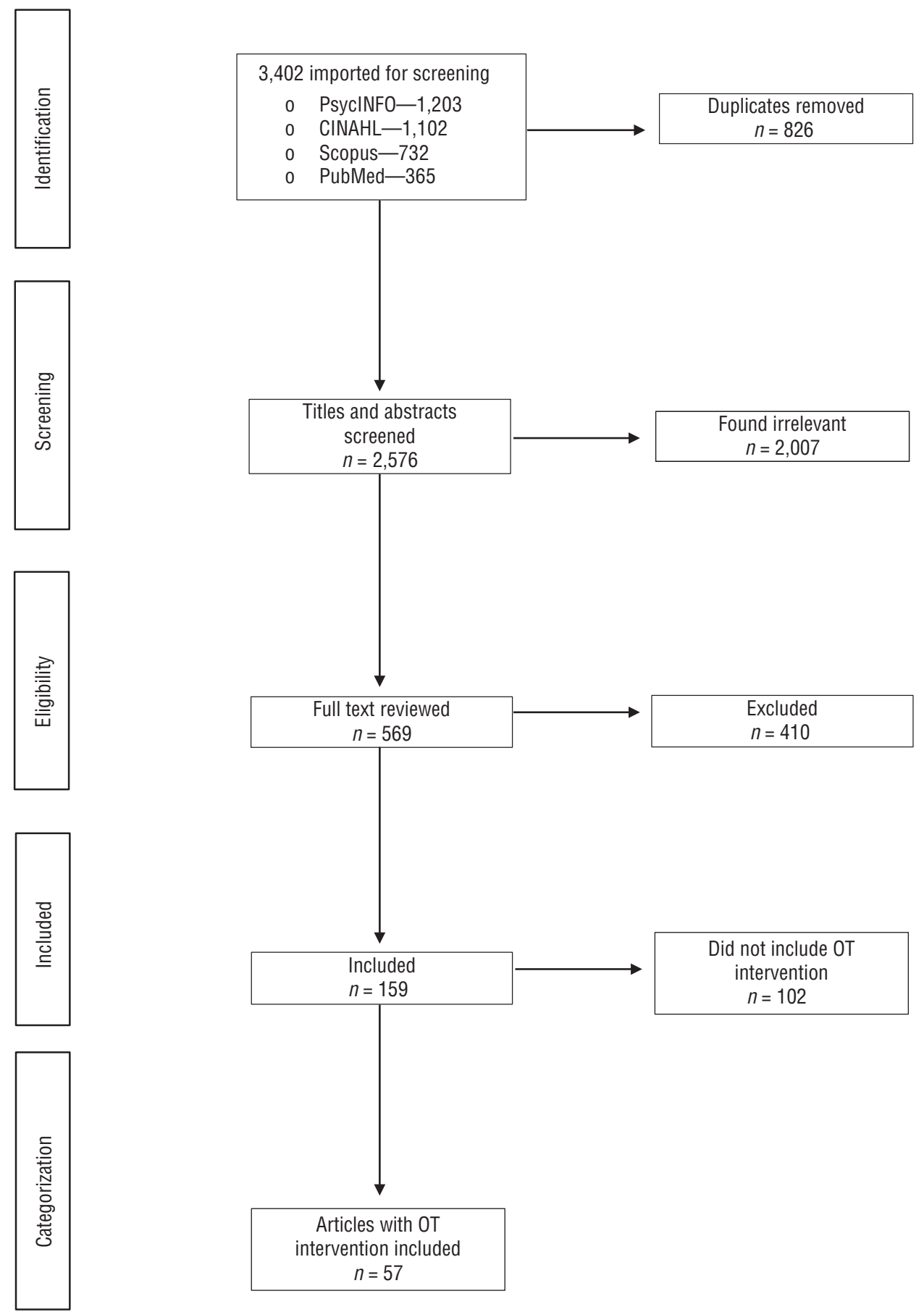

Note. OT = occupational therapy. Figure format from "Preferred Reporting Items for Systematic Reviews and Meta-Analyses: The PRISMA Statement," by D. Moher, A. Liberati, J. Tetzlaff, and D. G. Altman; PRISMA Group, 2009, PLoS Medicine, 6(7), e1000097. https://doi.org/10.1371/ journal.pmed.1000097

leisure and social interaction, and community participation. Intervention strategies used to reach each of these outcomes are discussed in the sections that follow, as is the intervention strategy of inclusive therapeutic process, which crossed multiple outcomes. 


\section{Activities of Daily Living}

The most common intervention outcome with adults with ID was improving or enhancing their ability to care for themselves and perform life activities (22 articles). Most articles were specifically about occupational therapy intervention to address ADLs. Three articles detailed interventions within the scope of occupational therapy practice but not provided by occupational therapy practitioners. Single-subject design ( $N=1-6$ participants) and pretest-posttest experimental design ( $N=44-77$ participants) were the most frequent types of studies used to measure ADL outcomes. ADL interventions targeted broad occupations such as morning routines and time management, client-selected daily life activities, or specific tasks such as functional mobility or exercise for health management (e.g., Arvidsson \& Jonsson, 2006; Hällgren \& Kottorp, 2005; Lotan et al., 2010; Nilsson et al., 2011).

Staff training and technology training were the most common strategies used to create change in ADL performance. Formal staff training combining classroom and on-site interaction improved how staff interacted with, prompted, and graded activities for adults with ID, resulting in increased ADL engagement (e.g., Stancliffe et al., 2008). Training to use technology also increased independence in ADL performance (e.g., Lotan et al., 2010; Nilsson et al., 2011). For example, one article suggested that adults with profound ID and multiple disabilities can learn to use power mobility with technology and caregiver supports, considerable practice (up to years), appropriate equipment referrals, and follow-up from practitioners (Nilsson et al., 2011). Habilitative approaches such as client education and practice were also effective in enhancing skills for ADLs (e.g., Hällgren \& Kottorp, 2005).

\section{Employment}

Eighteen articles focused on intervention with adults with ID to address occupational performance in employment or productive occupations. Ten of these articles identified occupational therapy as part of the intervention team, and an additional 2 articles had occupational therapy faculty among its authors. Researchers most frequently used singlesubject design or descriptive case studies to study employment interventions, and all but 1 of the articles included 5 or fewer adults with ID as participants.

These articles focused on improving specific job skills and job-related social skills for employment for adults with ID primarily through the use of prompting strategies, group skills training and practice, environmental modifications, and technology training (e.g., Cannella-Malone et al., 2017; Liu et al., 2013). Video modeling applications and creation of customized work spaces to support the physical, cognitive, and behavioral needs of adults with ID were deemed effective strategies for vocational training (Cannella-Malone et al., 2017; Gentry et al., 2012). Examples of workplace modifications included using visual supports, advocating for appropriate accommodations, or having a support person present (e.g., Ineson, 2015; Kramer et al., 2018). Environmental strategies to adapt both physical and social environments were effective to support self-determined decision making and to improve work performance (e.g., Mirza \& Hammel, 2009). Employment-related interventions for productive occupations with adults with profound ID focused on the use of technology-based prompting systems, practice, and reinforcers (e.g., food or drink) to increase their engagement in simple sorting tasks and activity transitions (e.g., Lancioni et al., 2015).

\section{Leisure and Social Interaction}

Ten articles provided evidence for interventions to enhance leisure and social interaction. All but 2 of these articles specified the role of occupational therapy in the intervention. Authors primarily used qualitative descriptions or singlesubject designs, although 3 studies involved designs with more than 20 participants. Specific leisure and social interaction outcomes included improving relationships between adults with ID and their caregivers and increasing participation in leisure activities, such as gardening or computer games (e.g., Sempik et al., 2014). 
Sensory strategies, technology training, and other specific intervention activities were the most common means to improve leisure and social interaction. Sensory strategies to manage sensory sensitivities, anxiety, and challenging behaviors demonstrated mixed results (e.g., Green et al., 2003; Kaplan et al., 2006). Specific therapeutic activities, such as horticulture programs and training to use virtual reality leisure programs, positively enhanced the social interaction skills and leisure participation of adults with ID (e.g., Sempik et al., 2014; Yalon-Chamovitz \& Weiss, 2008).

\section{Community Participation}

Six articles were found on interventions to improve community engagement for this population. Half of the articles included explicit discussion of occupational therapy involvement in the intervention, and occupational therapy practitioners wrote 1 additional article. Program evaluation was the most common method to study community participation, and most studies included more than 20 participants. Community participation outcomes included improvement in traveling in the community, navigating adult service systems, or engaging in other activities outside of the home (Berg et al., 2017; Stock et al., 2011; Zakrajsek et al., 2014). The most common interventions involved program classes, staff training, and technology applications to support adults' community participation (e.g., Stock et al., 2011; Zakrajsek et al., 2014).

\section{Inclusive Therapeutic Process}

Crossing multiple outcomes, 4 articles emphasized the benefit of explicit inclusion of adults with ID in the therapeutic process as an important means to create change (e.g., Ball \& Shanks, 2012; Dean et al., 2015). These articles noted that practitioners preferred informal discussion to gather and use feedback for service planning and that person-centered, multidisciplinary planning processes were integral to improving occupational engagement (Ball \& Shanks, 2012; Prakash et al., 2007). Focusing on client strengths and preferences coupled with coaching and collaboration with community partners was recommended to improve selfdetermination and occupational performance among adults with ID (Dean et al., 2015). Additionally, consumerdirected assistive technology with environmental modification improved client satisfaction (Mirza \& Hammel, 2009).

\section{Discussion}

The search for evidence supporting occupational therapy practice with adults with ID generated more articles than anticipated. Most intervention studies were published in non-occupational therapy journals, which may be contributing to an impression that limited evidence exists to support occupational therapy intervention with adults with ID. Many articles contained information relevant to occupational therapy intervention without explicitly stating whether occupational therapy practitioners were involved. This finding is consistent with prior research that showed that $82.8 \%$ of occupational therapy practitioners drew evidence-based practice information from non-occupational therapy sources (Döpp et al., 2012). However, occupational therapy-specific intervention evidence was also published in these journals.

Articles included in this scoping review described a range of habilitative and compensatory approaches involving technology training, prompting strategies (often through the use of technology), and caregiver training to improve occupational performance outcomes for adults with ID. In this scoping review, we also found a small body of literature on intervention strategies that occupational therapy practitioners can use to better engage people with profound intellectual and multiple disabilities. Moreover, literature emphasizing inclusive therapeutic processes highlighted the importance of prioritizing perspectives of adults with ID to improve occupational therapy outcomes. Learning the perspectives of adults with ID may require adaptations to traditional interview methods within the occupational therapy 
process because of cognitive impairments and potentially limited receptive and expressive communication skills (Ball \& Shanks, 2012).

Issues with ADLs or employment may represent typical reasons for referral to occupational therapy for adults with ID because they were the most common occupational outcomes in this scoping review. However, employment may be overrepresented because including occupation as a search term helped capture work and employment articles beyond occupational therapy-specific literature, thus increasing the total number of articles included in this scoping review. Several articles emphasized emerging and distinct roles for occupational therapy practitioners working with adults with ID in the areas of behavior management, inclusive education and employment, care coordination, and advocacy (e.g., Dean et al., 2015; Parkinson et al., 2009; Prakash et al., 2007). Although these articles present a myriad of growth opportunities for occupational therapy practice with adults with ID, practitioners may need support to provide care coordination services that fall outside of traditional occupational therapy roles (Parkinson et al., 2009).

Reemergent occupational therapy roles in mental health promotion may help adults with ID manage challenging behaviors and anxiety that affect their occupational performance. Leisure and community participation articles provided examples of mental health promotion interventions (e.g., Graham et al., 2016; Green et al., 2003). Psychosocialfocused occupational therapy intervention is important as more adults with ID with comorbid mental health diagnoses gain access to inclusive community spaces (Blaskowitz et al., 2019; Urwin \& Ballinger, 2005).

Small sample designs, including case studies and single-subject designs, were most frequently used in the studies included in this scoping review. This finding may speak to challenges in recruiting adults with ID, who are considered a vulnerable population with extra research protections. Although small sample designs can limit the generalizability of research findings, they are often the more appropriate design choice for research with adults with ID because of the wide variability of skills within this population and the need to individualize intervention strategies to meet their specialized needs. Occupational therapy practitioners working with adults with ID in clinical or community-based settings can easily translate findings from small sample design research into practice and track the effects of their intervention with this population.

This review builds on findings from recent reviews with similar populations (Bathje et al., 2018; Waldman-Levi et al., 2019). The specific populations for each review differed in that Waldman-Levi et al. (2019) included adolescents, Bathje et al. (2018) included people without ID, and both previous reviews excluded people with profound ID. Therefore, although some overlap occurred in the articles included in each review, this review included multiple new articles. By including the full range of levels of ID and a broader scope of interventions relevant to occupational therapy, we extended intervention outcomes found beyond those of employment and ADLs and IADLs. Intervention strategies encompassed those not represented in recent reviews, such as caregiver training and environmental modifications. Moreover, by including nonresearch articles published in peer-reviewed journals, this review also provides information about the broad role of occupational therapy with this population and the importance of inclusive practices to seek and use perspectives of adults with ID in the occupational therapy process.

It is challenging to capture all relevant literature on intervention with adults with ID, whether for research or evidencebased practice. Many interventions relevant to occupational therapy are published in developmental disability literature that occupational therapy practitioners may not regularly access. When reviewing literature, the distinctions between ID and the broader categories of neurodevelopmental or developmental disability may be unclear; in addition, it may not be explicit whether ID coexists with other developmental conditions, such as cerebral palsy or ASD. Moreover, studies with people with cognitive disabilities may not specifically state whether ID is included. The prevalence of relevant literature from the United Kingdom sparks another source of potential confusion because ID is labeled as learning disability in the United Kingdom. Specific learning disability (termed learning difficulty in the United Kingdom) is substantially different from ID, but the population included in an article may be ambiguous. 
Although the findings of this study are broad, the primary limitation is that relevant articles were likely missed. The variation in terminology for adults with ID and difficulty capturing interventions that do not explicitly mention occupational therapy are major aspects of this challenge. Although we used multiple strategies to develop search terms and consulted with a librarian, this area should be further explored. Moreover, because the initial search yielded so many articles, we did not complete hand searching or reference list reviews that may have yielded additional results.

Opportunities exist for future research to support occupational therapy intervention with adults with ID. The bulk of the existing evidence includes ADLs or employment outcomes; further research may address community participation, leisure, social interaction, and mental health promotion. Few articles included people with severe or profound ID; additional research is needed with this population. Technology-related interventions were among the most common; these interventions could be expanded to explore different technological advances and to consider the broad range of intervention strategies appropriate with this population. Findings also imply that sufficient evidence may be present for a systematic review that evaluates the strength and rigor as well as quality of intervention evidence to support occupational therapy practice with adults with ID.

\section{Implications for Occupational Therapy Practice}

The results of this scoping review have the following implications for occupational therapy practice:

- Occupational therapy practitioners need to explicitly seek and use the perspectives of adults with ID with whom they work to ensure inclusive and person-centered practice.

- Occupational therapy practitioners have distinct skills to support adults with ID with participation in a broad range of occupations and may need to advocate for their role in promoting community participation, social interaction, and mental health.

- Evidence supports a wide variety of compensatory and habilitative approaches with adults with ID; moreover, a combination of approaches may be appropriate, especially when using technology or caregiver prompting to support participation.

- When searching for occupational therapy-related evidence for adults with ID, occupational therapy practitioners need to search broadly to include journals outside of occupational therapy and consider search terms carefully.

\section{Conclusion}

Research and policy-related evidence that can inform occupational therapy practice with adults with ID exists; however, occupational therapy practitioners may not be knowledgeable of or have access to the full range of literature available. This scoping review demonstrates that evidence published in occupational therapy and non-occupational therapy journals supports occupational therapy intervention with adults with ID. Using broad search strategies that generate evidence beyond occupational therapy publications may bridge perceived gaps in evidence-based practice with adults with ID. Occupational therapy practitioners can play a vital role in supporting adults with ID to live meaningful lives according to their preferences and use existing evidence to support expanding their role with this population.

\section{References}

American Association on Intellectual and Developmental Disabilities. (n.d.). Definition of intellectual disability. http://aaidd.org/intellectual-disability/ definition\#.WdOb5GhSyUk

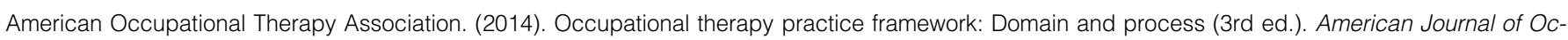
cupational Therapy, 68(Suppl.1), S1-S48. https://doi.org/10.5014/ajot.2014.682006

${ }^{*}$ Applegate, S. L., Rice, M. S., Stein, F., \& Maitra, K. K. (2008). Knowledge of results and learning to tell the time in an adult male with an intellectual disability: A single-subject research design. Occupational Therapy International, 15, 32-44. https://doi.org/10.1002/oti.242

*Arikawa, M., Goto, H., \& Mineno, K. (2013). Job support by occupational therapists for people with developmental disabilities: Two case studies. Work, 45, 245-251. https://doi.org/10.3233/WOR-131590

*Indicates studies included in the scoping review. 
Arksey, H., \& O'Malley, L. (2005). Scoping studies: Towards a methodological framework. International Journal of Social Research Methodology, 8, $19-32$. https://doi.org/10.1080/1364557032000119616

*Arvidsson, G., \& Jonsson, H. (2006). The impact of time aids on independence and autonomy in adults with developmental disabilities. Occupational Therapy International, 13, 160-175. https://doi.org/10.1002/oti.215

*Aspinall, A., \& Nichols, E. (2008). TATE case study. Disability and Rehabilitation: Assistive Technology, 3, 236-239. https://doi.org/10.1080/ 17483100801921121

*Ball, J., \& Shanks, A. (2012). Gaining feedback from people with learning disabilities. British Journal of Occupational Therapy, 75, 471-477. https://doi.org/10. 4276/030802212X13496921049743

Bathje, M., Lannoye, M., Mercier, A., \& Panter, K. (2018). A review of occupation-based life skills interventions for adults with neurodevelopmental disorders. Occupational Therapy in Mental Health, 34, 165-180. https://doi.org/10.1080/0164212X.2017.1360168

*Benford, F. (2017). Use of powered mobility for a young adult with profound and multiple learning disabilities: A practice analysis. British Journal of Occupational Therapy, 80, 517-520. https://doi.org/10.1177/030822617698169

*Berg, L. A., Jirikowic, T., Haerling, K., \& MacDonald, G. (2017). Navigating the hidden curriculum of higher education for postsecondary students with intellectual disabilities. American Journal of Occupational Therapy, 71, 7103100020. https://doi.org/10.5014/ajot.2017.024703

Blaskowitz, M. G., Hernandez, B., \& Scott, P. W. (2019). Predictors of emergency room and hospital utilization among adults with intellectual and developmental disabilities (IDD). Intellectual and Developmental Disabilities, 57, 127-145. https://doi.org/10.1352/1934-9556-57.2.127

*Borioni, N., Marinaro, P., Celestini, S., Del Sole, F., Magro, R., Zoppi, D., .. Bonassi, S. (2012). Effect of equestrian therapy and onotherapy in physical and psycho-social performances of adults with intellectual disability: A preliminary study of evaluation tools based on the ICF classification. Disability and Rehabilitation, 34, 279-287. https://doi.org/10.3109/09638288.2011.605919

Brown, D. (2014). Habilitative services: An essential health benefit and an opportunity for occupational therapy practitioners and consumers. American Journal of Occupational Therapy, 68, 130-138. https://doi.org/10.5014/ajot.2014.682001

*Bunning, K., Kwiatkowska, G., \& Weldin, N. (2012). People with profound and multiple intellectual disabilities using symbols to control a computer: Exploration of user engagement and supporter facilitation. Assistive Technology, 24, 259-270. https://doi.org/10.1080/10400435.2012.659832

${ }^{*}$ Campbell, J. E., Morgan, M., Barnett, V., \& Spreat, S. (2015). Handheld devices and video modeling to enhance the learning of self-help skills in adolescents with autism spectrum disorder. OTJR: Occupation, Participation and Health, 35, 95-100. https://doi.org/10.1177/1539449215570040

*Cannella-Malone, H. I., Chan, J. M., \& Jimenez, E. D. (2017). Comparing self-directed video prompting to least-to-most prompting in post-secondary students with moderate intellectual disabilities. International Journal of Developmental Disabilities, 63, 211-220. https://doi.org/10.1080/20473869.2017. 1301695

${ }^{*}$ Castelhano, N., Silva, F., Rezende, M., Roque, L., \& Magalhães, L. (2013). Ludic content in multisensory stimulation environments: An exploratory study about practice in Portugal. Occupational Therapy International, 20, 134-143. https://doi.org/10.1002/oti.1347

${ }^{*}$ Chan, K. H. A., Varahan, J. L., Loh, P. L. D., \& Tan, S. I. (2011). A demonstration of helping adolescents with mild intellectual disability climb ladders. Journal of Policy and Practice in Intellectual Disabilities, 8, 283-289. https://doi.org/10.1111/j.1741-1130.2011.00322.x

*Dean, E. E., Dunn, W., \& Tomchek, S. (2015). Role of occupational therapy in promoting self-determination through consumer-directed supports. Occupational Therapy in Health Care, 29, 86-95. https://doi.org/10.3109/07380577.2014.958887

*de Paula Nunes Sobrinho, F., \& de Lucena, U. F. (2012). Ergonomics and the inclusion of people with disabilities in a Brazilian workplace. Work, 41(Suppl. 1), 4709-4715. https://doi.org/10.3233/WOR-2012-0022-4709

Döpp, C. M., Steultjens, E. M., \& Radel, J. (2012). A survey of evidence-based practise among Dutch occupational therapists. Occupational Therapy International, 19, 17-27. https://doi.org/10.1002/oti.324

*Gentry, T., Lau, S. J., Molinelli, A., Fallen, A., \& Kriner, R. (2012). The Apple iPod Touch as a vocational support aid for adults with autism: Three case studies. Journal of Vocational Rehabilitation, 37, 75-85. https://doi.org/10.3233/JVR-2012-0601

*Graham, A., Harbottle, C., \& King, D. (2016). Resolve: A community-based forensic learning disability service specialising in supporting male sex offenders-Our model, approach and evidence base for effective intervention. Journal of Intellectual Disabilities and Offending Behaviour, 7, 186-194. https://doi.org/10.1108/JIDOB-10-2014-0014

*Green, D., Beaten, L., Moore, D., Warren, L., Wick, V., Sanford, J. E., \& Santosh, P. (2003). Clinical incidence of sensory integration difficulties in adults with learning disabilities and illustration of management. British Journal of Occupational Therapy, 66, 454-463. https://doi.org/10.1177/030802260306601004

*Grolla, E., Andrighetto, G., Parmigiani, P., Hladnik, U., Ferrari, G., Bernardelle, R., . . Dolcetta, D. (2011). Specific treatment of Prader-Willi syndrome through cyclical rehabilitation programmes. Disability and Rehabilitation, 33, 1837-1847. https://doi.org/10.3109/09638288.2010.549288

*Hällgren, M., \& Kottorp, A. (2005). Effects of occupational therapy intervention on activities of daily living and awareness of disability in persons with intellectual disabilities. Australian Occupational Therapy Journal, 52, 350-359. https://doi.org/10.1111/j.1440-1630.2005.00523.x

Harmuth, E., Silletta, E., Bailey, A., Adams, T., Beck, C., \& Barbic, S. P. (2018). Barriers and facilitators to employment for adults with autism: A scoping review. Annals of International Occupational Therapy, 1, 31-40. https://doi.org/10.3928/24761222-20180212-01

*Harr, N., Dunn, L., \& Price, P. (2011). Case study on effect of household task participation on home, community, and work opportunities for a youth with multiple disabilities. Work, 39, 445-453. https://doi.org/10.3233/WOR-2011-1194

*Hutchinson, N. L., Versnel, J., Chin, P., \& Munby, H. (2008). Negotiating accommodations so that work-based education facilitates career development for youth with disabilities. Work, 30, 123-136. 
*Ineson, R. (2015). Exploring paid employment options with a person with severe learning disabilities and high support needs: An exploratory case study. British Journal of Occupational Therapy, 78, 58-65. https://doi.org/10.1177/0308022614561234

Johnson, K. R., Blaskowitz, M., \& Mahoney, W. (2019). Occupational therapy practice with adults with intellectual disability: What more can we do? Open Journal of Occupational Therapy, 7(2). https://doi.org/10.15453/2168-6408.1573

*Kaplan, H., Clopton, M., Kaplan, M., Messbauer, L., \& McPherson, K. (2006). Snoezelen multi-sensory environments: Task engagement and generalization. Research in Developmental Disabilities, 27, 443-455. https://doi.org/10.1016/j.ridd.2005.05.007

*Kjellberg, A., Kåhlin, I., Haglund, L., \& Taylor, R. R. (2012). The myth of participation in occupational therapy: Reconceptualizing a client-centred approach. Scandinavian Journal of Occupational Therapy, 19, 421-427. https://doi.org/10.3109/11038128.2011.627378

*Koritsas, S., lacono, T., Hamilton, D., \& Leighton, D. (2008). The effect of active support training on engagement, opportunities for choice, challenging behaviour and support needs. Journal of Intellectual and Developmental Disability, 33, 247-256. https://doi.org/10.1080/13668250802282944

*Kottorp, A., Hällgren, M., Bernspång, B., \& Fisher, A. G. (2003). Client-centered occupational therapy for persons with mental retardation: Implementation of an intervention programme in activities of daily living tasks. Scandinavian Journal of Occupational Therapy, 10, 52-60. https://doi.org/10.1080/ 11038120310009416

*Kramer, J. M., Ryan, C. T., Moore, R., \& Schwartz, A. (2018). Feasibility of electronic peer mentoring for transition-age youth and young adults with intellectual and developmental disabilities: Project Teens making Environment and Activity Modifications. Journal of Applied Research in Intellectual Disabilities, 31 , e118-e129. https://doi.org/10.1111/jar.12346

*Lancioni, G. E., O'Reilly, M. F., Singh, N. N., Pidala, S., Piazzolla, G., Oliva, D., \& Groeneweg, J. (2006). A social validation assessment of cooperative versus individual task engagement of persons with multiple disabilities. Journal of Visual Impairment and Blindness, 100, 169-173. https://doi.org/10.1177/ $0145482 \times 0610000306$

*Lancioni, G. E., Singh, N. N., O'Reilly, M. F., Green, V. A., Oliva, D., \& Campodonico, F. (2013). Two men with multiple disabilities carry out an assembly work activity with the support of a technology system. Developmental Neurorehabilitation, 16, 332-339. https://doi.org/10.3109/17518423.2012.736419

*Lancioni, G. E., Singh, N. N., O’Reilly, M. F., Sigafoos, J., Alberti, G., Boccasini, A., . . Trubia, G. (2015). Assistive technology to support occupational engagement and mobility in persons with multiple disabilities. Life Span and Disability, 18, 119-139.

*Lancioni, G. E., Singh, N. N., O'Reilly, M. F., Sigafoos, J., Alberti, G., Perilli, V., . . Groeneweg, J. (2014). People with multiple disabilities learn to engage in occupation and work activities with the support of technology-aided programs. Research in Developmental Disabilities, 35, 1264-1271. https://doi.org/ 10.1016/j.ridd.2014.03.026

*Lancioni, G. E., Singh, N. N., O'Reilly, M. F., Sigafoos, J., Oliva, D., Campodonico, F., \& Groeneweg, J. (2008). Assisting persons with multiple disabilities to move through simple occupational activities with automatic prompting. Research in Developmental Disabilities, 29, 439-446. https://doi.org/10.1016/j. ridd.2007.08.002

*Liu, K. P., Wong, D., Chung, A. C., Kwok, N., Lam, M. K., Yuen, C. M., .. Kwan, A. C. S. (2013). Effectiveness of a workplace training programme in improving social, communication and emotional skills for adults with autism and intellectual disability in Hong Kong-A pilot study. Occupational Therapy International, 20, 198-204. https://doi.org/10.1002/oti.1356

*Lotan, M., Yalon-Chamovitz, S., \& Weiss, P. L. (2009). Improving physical fitness of individuals with intellectual and developmental disability through a virtual reality intervention program. Research in Developmental Disabilities, 30, 229-239. https://doi.org/10.1016/j.ridd.2008.03.005

*Lotan, M., Yalon-Chamovitz, S., \& Weiss, P. L. (2010). Virtual reality as means to improve physical fitness of individuals at a severe level of intellectual and developmental disability. Research in Developmental Disabilities, 31, 869-874. https://doi.org/10.1016/j.ridd.2010.01.010

*Lotan, M., Yalon-Chamovitz, S., \& Weiss, P. L. (2011). Training caregivers to provide virtual reality intervention for adults with severe intellectual and developmental disability. Journal of Physical Therapy Education, 25, 15-19. https://doi.org/10.1097/00001416-201110000-00004

*Mead, L., Mead, L., Sebuliba, P., \& Williams, L. (2010). Community cohesion: Creating and using interactive whiteboard games. Journal of Assistive Technologies, 4, 40-44. https://doi.org/10.5042/jat.2010.0664

*Mihailidis, A., Melonis, M., Keyfitz, R., Lanning, M., Van Vuuren, S., \& Bodine, C. (2016). A nonlinear contextually aware prompting system (N-CAPS) to assist workers with intellectual and developmental disabilities to perform factory assembly tasks: System overview and pilot testing. Disability and Rehabilitation: Assistive Technology, 11, 604-612. https://doi.org/10.3109/17483107.2015.1063713

*Mirza, M., \& Hammel, J. (2009). Consumer-directed goal planning in the delivery of assistive technology services for people who are ageing with intellectual disabilities. Journal of Applied Research in Intellectual Disabilities, 22, 445-457. https://doi.org/10.1111/j.1468-3148.2009.00495.x

*Nilsson, L., Eklund, M., Nyberg, P., \& Thulesius, H. (2011). Driving to learn in a powered wheelchair: The process of learning joystick use in people with profound cognitive disabilities. American Journal of Occupational Therapy, 65, 652-660. https://doi.org/10.5014/ajot.2011.001750

*Olivier, M., Oosthuizen, L., \& Casteleijn, D. (2007). Occupational therapy students' contribution towards enabling potential in a semi-rural community. Work, 29 , 63-68.

*Pal, J., Hale, L., \& Mirfin-Veitch, B. (2013). Experiences of therapists trying to reduce falls risk for people with intellectual disability. Journal of Policy and Practice in Intellectual Disabilities, 10, 314-320. https://doi.org/10.1111/jppi.12058

*Parkinson, S., Forsyth, K., Durose, S., Mason, R., \& Harris, D. (2009). The balance of occupation-focused and generic tasks within a mental health and learning disability occupational therapy service. British Journal of Occupational Therapy, 72, 366-370. https://doi.org/10.1177/030802260907200807

Patient Protection and Affordable Care Act, Pub. L. 111-148, 42 U.S.C. §§ 18001-18121 (2010).

*Perez, M., Carlson, G., Ziviani, J., \& Cuskelly, M. (2012). Contribution of occupational therapists in positive behaviour support. Australian Occupational Therapy Journal, 59, 428-436. https://doi.org/10.1111/j.1440-1630.2012.01036.x 
*Prakash, J., Andrews, T., \& Porter, I. (2007). Service innovation: Assertive outreach teams for adults with learning disability. Psychiatric Bulletin, 31 , $138-141$. https://doi.org/10.1192/pb.bp. 105.004648

*Rice, M. S., \& Hernandez, H. G. (2006). Frequency of knowledge of results and motor learning in persons with developmental delay. Occupational Therapy International, 13, 35-48. https://doi.org/10.1002/oti.206

*Sempik, J., Rickhuss, C., \& Beeston, A. (2014). The effects of social and therapeutic horticulture on aspects of social behaviour. British Journal of Occupational Therapy, 77, 313-319. https://doi.org/10.4276/030802214X14018723138110

*Stancliffe, R. J., Harman, A. D., Toogood, S., \& McVilly, K. R. (2008). Staff behaviour and resident engagement before and after active support training. Journal of Intellectual and Developmental Disability, 33, 257-270. https://doi.org/10.1080/13668250802318284

*Stock, S. E., Davies, D. K., Wehmeyer, M. L., \& Lachapelle, Y. (2011). Emerging new practices in technology to support independent community access for people with intellectual and cognitive disabilities. NeuroRehabilitation, 28, 261-269. https://doi.org/10.3233/NRE-2011-0654

${ }^{*}$ Toogood, S. (2008). Interactive training. Journal of Intellectual and Developmental Disability, 33, 215-224. https://doi.org/10.1080/13668250802292596

*Totsika, V., Toogood, S., Hastings, R. P., \& Nash, S. (2008). Interactive training for active support: Perspectives from staff. Journal of Intellectual and Developmental Disability, 33, 225-238. https://doi.org/10.1080/13668250802283348

*Urwin, R., \& Ballinger, C. (2005). The effectiveness of sensory integration therapy to improve functional behaviour in adults with learning disabilities: Five single-case experimental designs. British Journal of Occupational Therapy, 68, 56-66. https://doi.org/10.1177/030802260506800202

*Waight, M. P., \& Oldreive, W. J. (2012). Evaluating the ability of and enabling a blind adult with learning disability to sign a tenancy agreement. British Journal of Learning Disabilities, 40, 55-61. https://doi.org/10.1111/j.1468-3156.2011.00683.x

Waldman-Levi, A., Golisz, K., Swierat, R. P., \& Toglia, J. (2019). Scoping review: Interventions that promote functional performance for adolescents and adults with intellectual and developmental disabilities. Australian Occupational Therapy Journal, 66, 458-468. https://doi.org/10.1111/1440-1630.12577

*Weiss, P. L., Bialik, P., \& Kizony, R. (2003). Virtual reality provides leisure time opportunities for young adults with physical and intellectual disabilities. Cyberpsychology and Behavior, 6, 335-342. https://doi.org/10.1089/109493103322011650

Williamson, H. J., Contreras, G. M., Rodriguez, E. S., Smith, J. M., \& Perkins, E. A. (2017). Health care access for adults with intellectual and developmental disabilities: A scoping review. OTJR: Occupation, Participation and Health, 37, 227-236. https://doi.org/10.1177/1539449217714148

*Yalon-Chamovitz, S., \& Weiss, P. L. (2008). Virtual reality as a leisure activity for young adults with physical and intellectual disabilities. Research in Developmental Disabilities, 29, 273-287. https://doi.org/10.1016/j.ridd.2007.05.004

*Zakrajsek, A. G., Hammel, J., \& Scazzero, J. A. (2014). Supporting people with intellectual and developmental disabilities to participate in their communities through support staff pilot intervention. Journal of Applied Research in Intellectual Disabilities, 27, 154-162. https://doi.org/10.1111/jar.12060

Meghan G. Blaskowitz, DrPH, MOTR/L, is Assistant Professor, Department of Occupational Therapy, Duquesne University, Pittsburgh, PA; blaskowitz@duq.edu

Khalilah R. Johnson, PhD, MS, OTR/L, is Assistant Professor, Division of Occupational Science and Occupational Therapy, University of North Carolina School of Medicine, Chapel Hill.

Theodore Bergfelt, MLS, is Humanities Librarian, Gumberg Library, Duquesne University, Pittsburgh, PA.

Wanda J. Mahoney, PhD, OTR/L, is Associate Professor of Occupational Therapy and Medicine, Program in Occupational Therapy, Washington University School of Medicine, St. Louis, MO.

\section{Acknowledgments}

We thank David Nolfi (Head Librarian for Research Engagement, Health Sciences/STEM [Science, Technology, Engineering, and Mathematics] Initiatives, and Assessment at Duquesne University) for his methodological consultation and support in establishing search strategies for this scoping review. We also thank Emily Casile (occupational therapy student at Duquesne University) and Lindsey Wethington (occupational therapy student at Washington University) for assistance with editing this scoping review, the supplemental tables, and the figure. 


\section{Appendix. Supplemental Tables}

Table A.1. Selected Terms Used in Database Searches

\begin{tabular}{|c|c|c|}
\hline Condition & Age & Occupational Therapy Terms \\
\hline 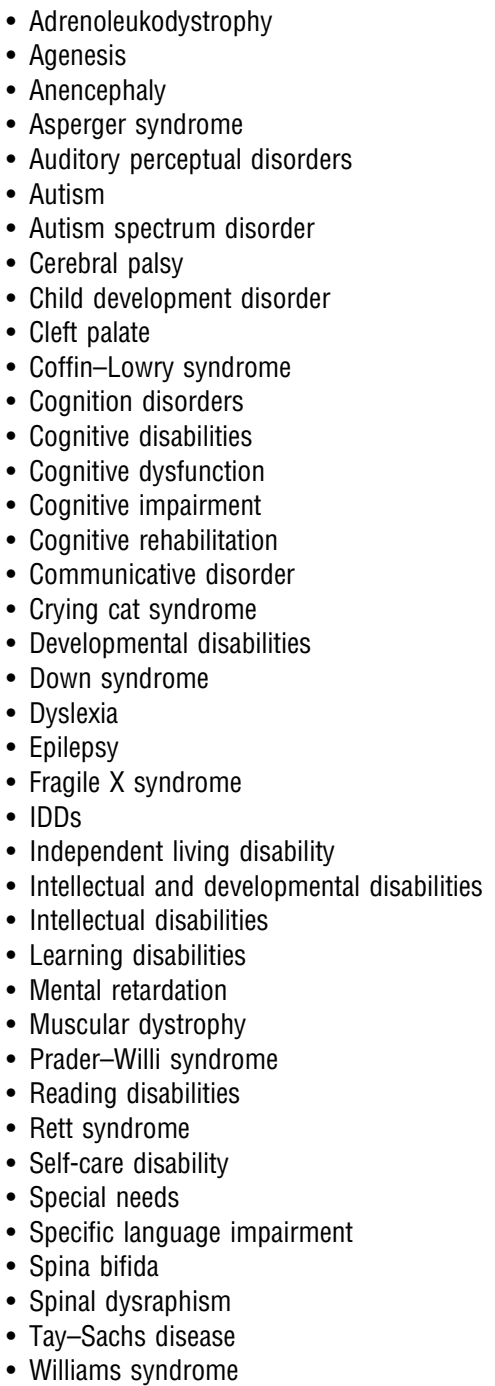 & $\begin{array}{l}\text { - Adult } \\
\text { - Adulthood } \\
\text { - Aged } \\
\text { - Elder } \\
\text { - Elderly } \\
\text { - Middle aged } \\
\text { - Older adult } \\
\text { - Old people } \\
\text { - Old person } \\
\text { - Senior citizen } \\
\text { - Thirties } \\
\text { - Very old } \\
\text { - Young adult }\end{array}$ & $\begin{array}{l}\text { - Education, occupational therapy } \\
\text { - Home occupational therapy } \\
\text { - Occupational science } \\
\text { - Occupational therapists } \\
\text { - Occupational therapy } \\
\text { - Occupational therapy assessment } \\
\text { - Occupational therapy practice } \\
\text { - Research, occupational therapy }\end{array}$ \\
\hline
\end{tabular}

Note. The terms in this table represent the main concepts included in all searches, although the exact terms used may have differed depending on the expression of concepts by specific controlled vocabularies and whether truncation could have been used. When possible, automatic term explosion was used. IDDs $=$ intellectual and developmental disabilities. 


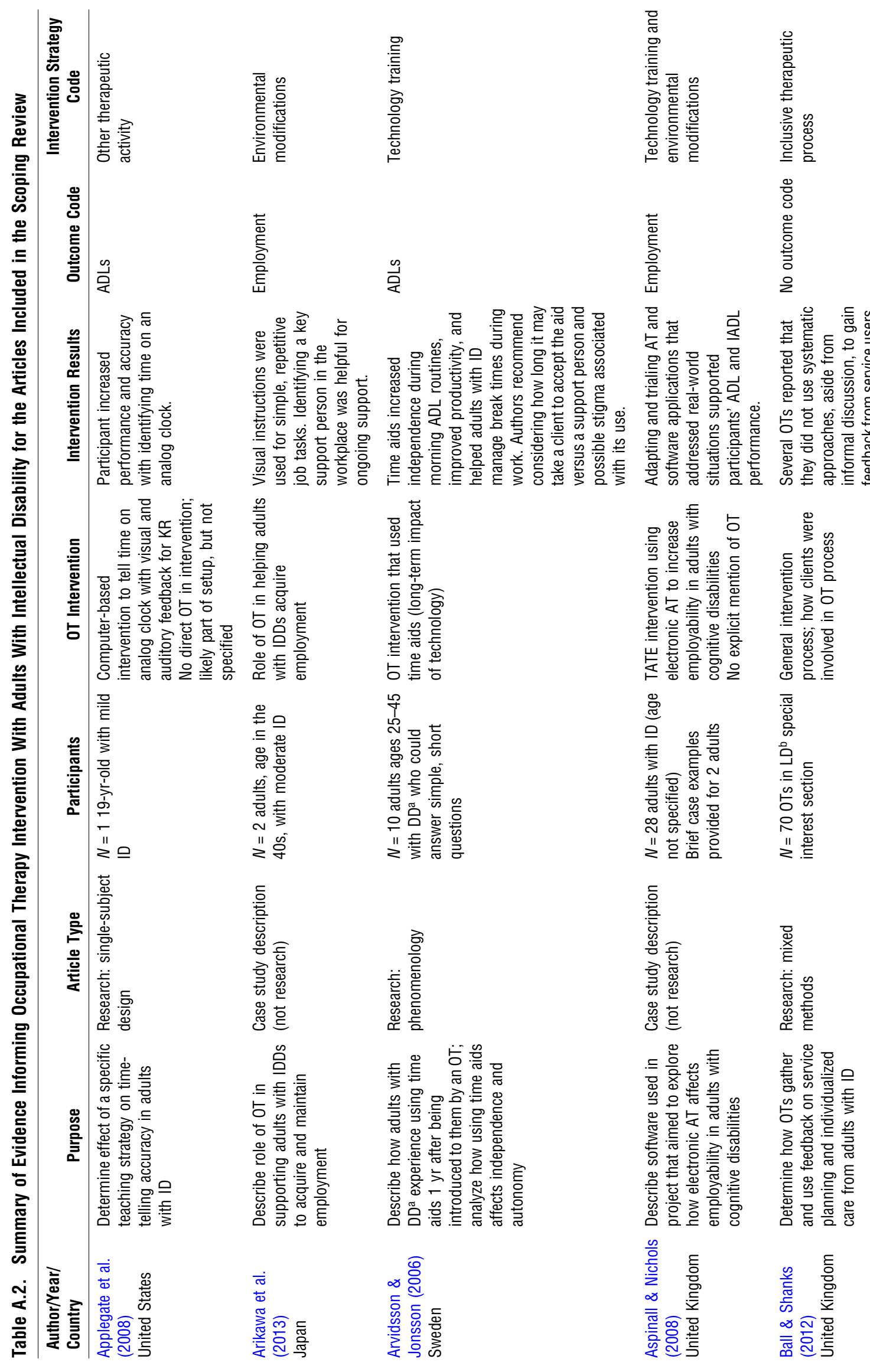




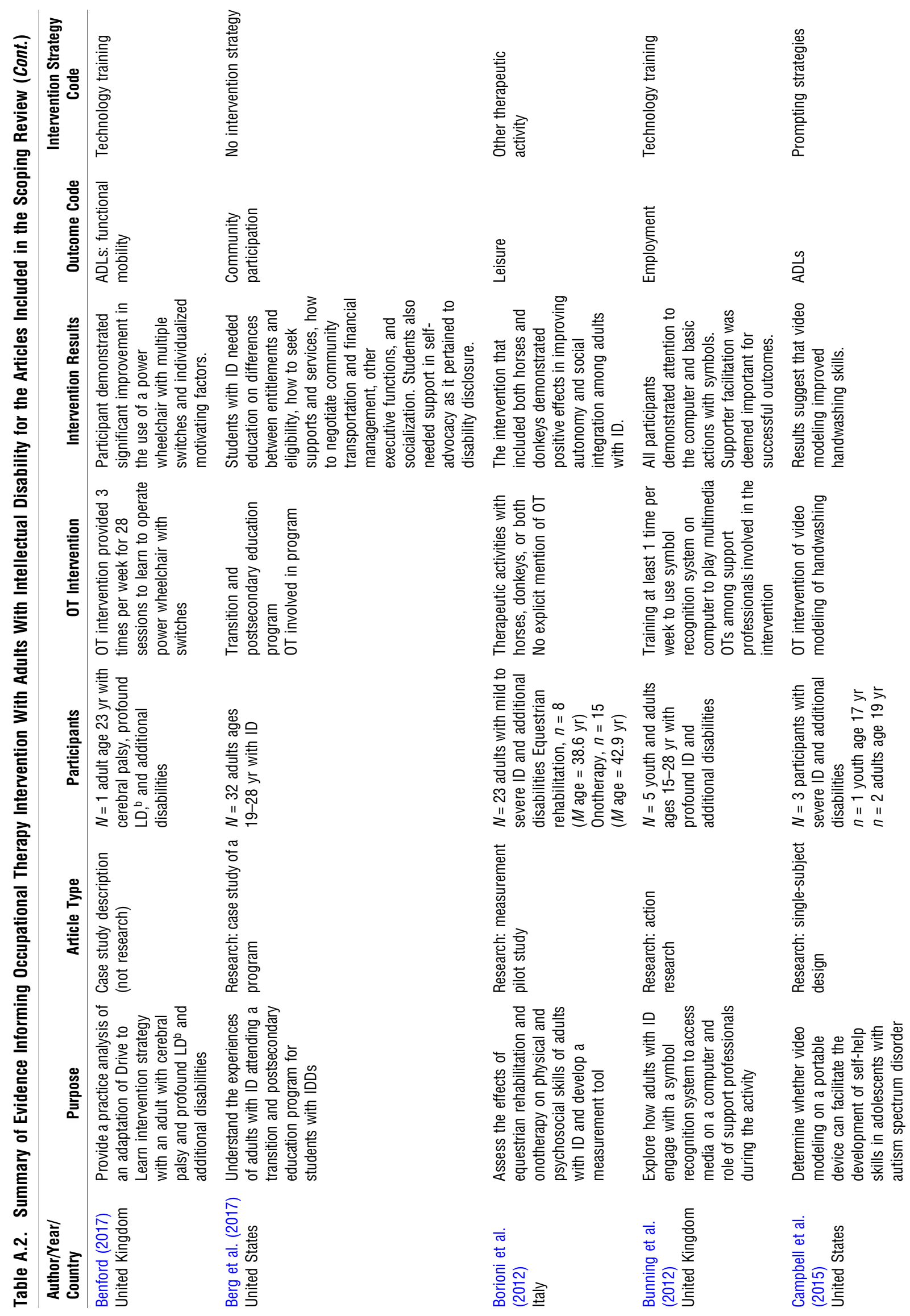



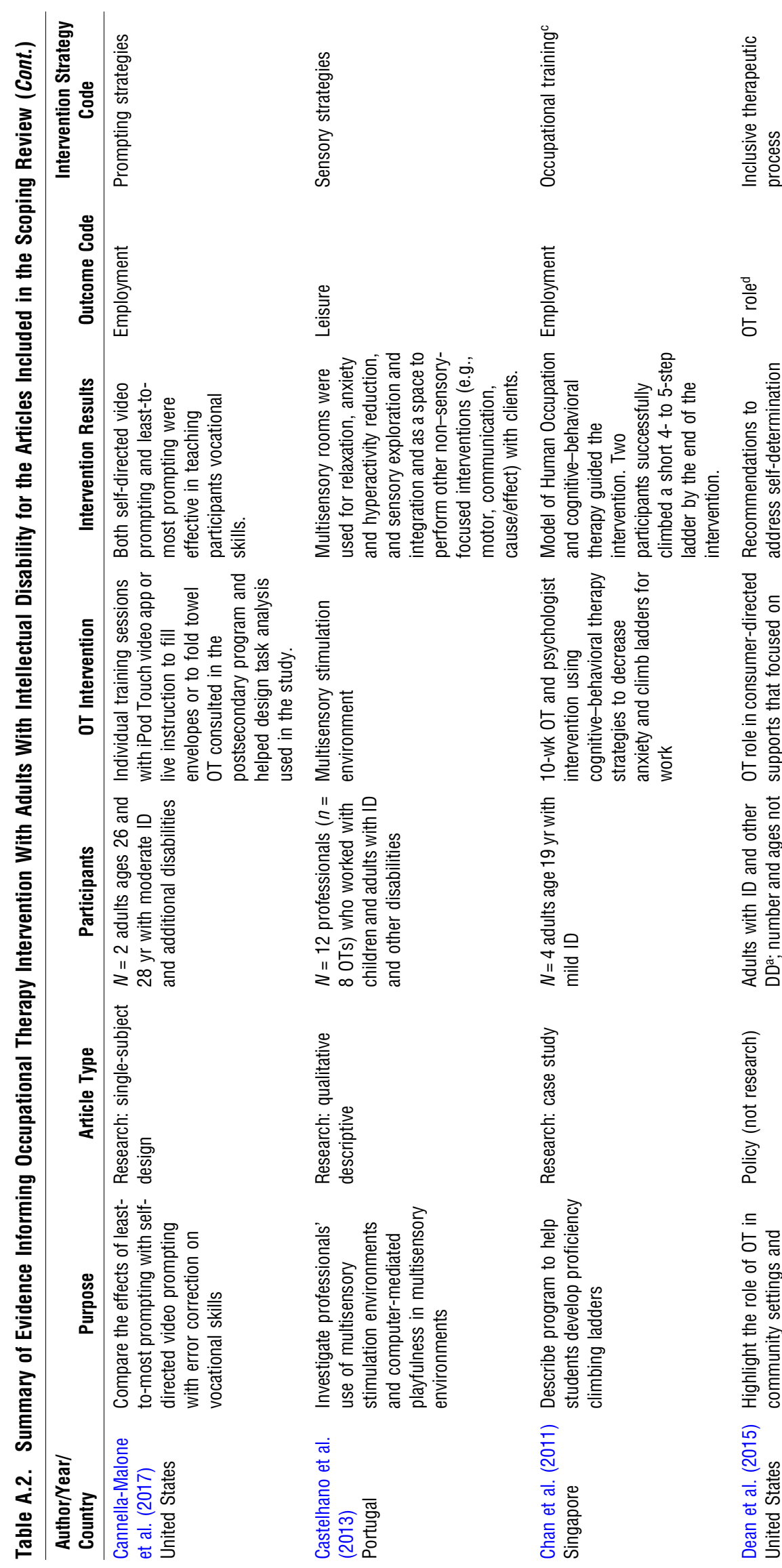

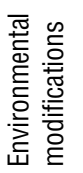

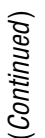

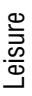

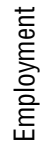

$\frac{\text { 흔 }}{\frac{5}{\circ}}$

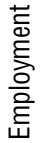

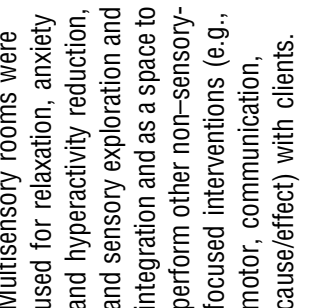

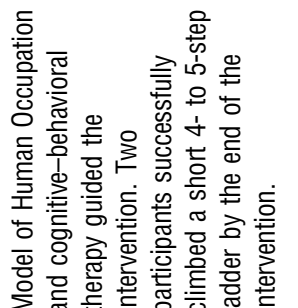

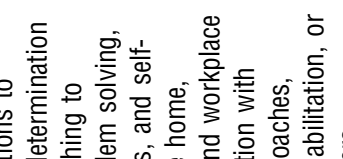

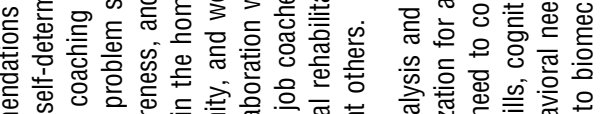

क क ष

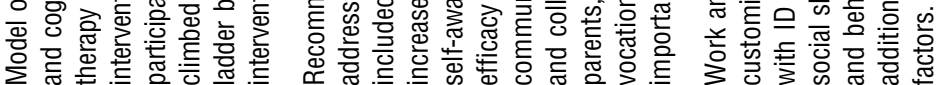

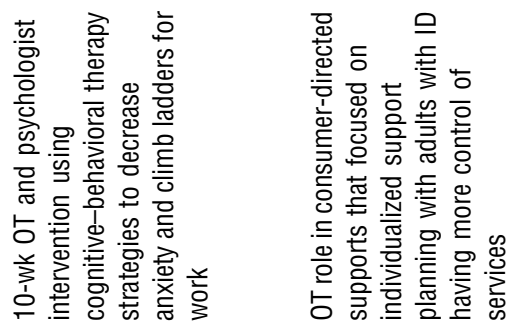

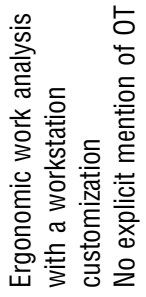
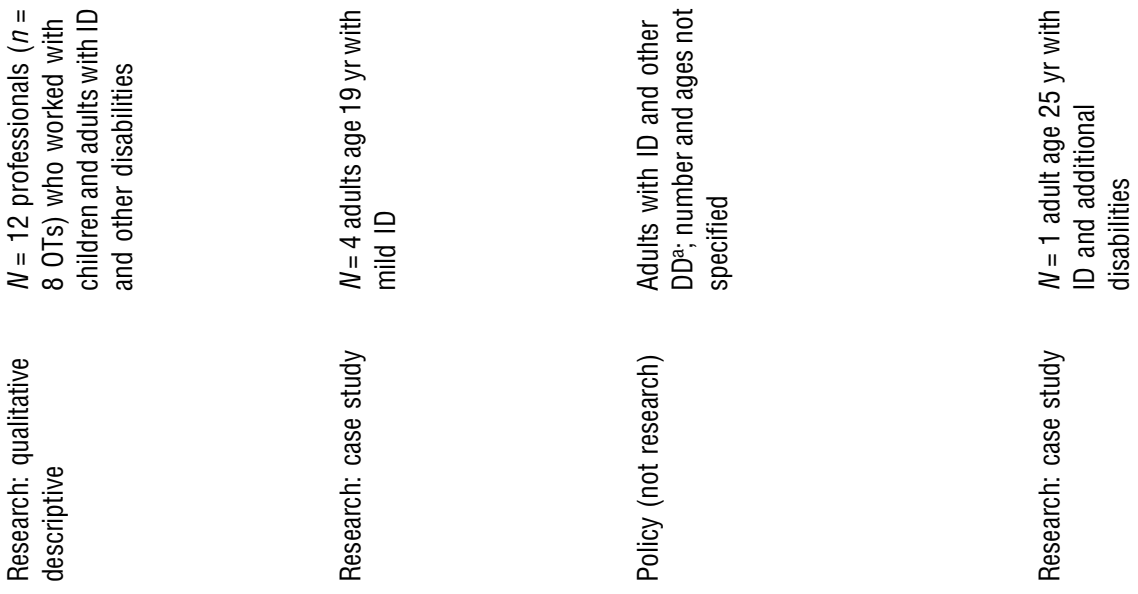

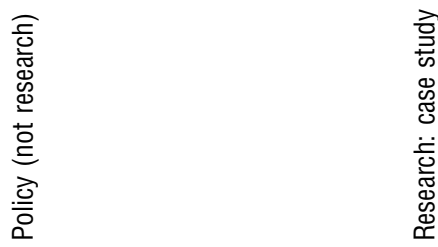
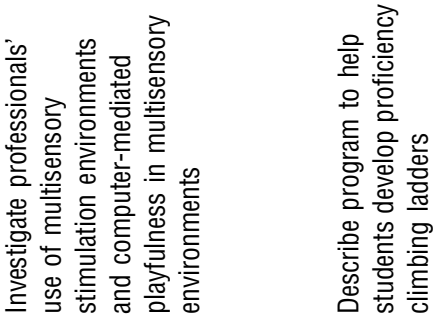

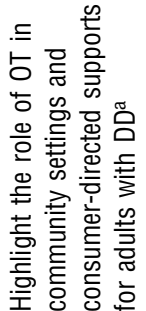
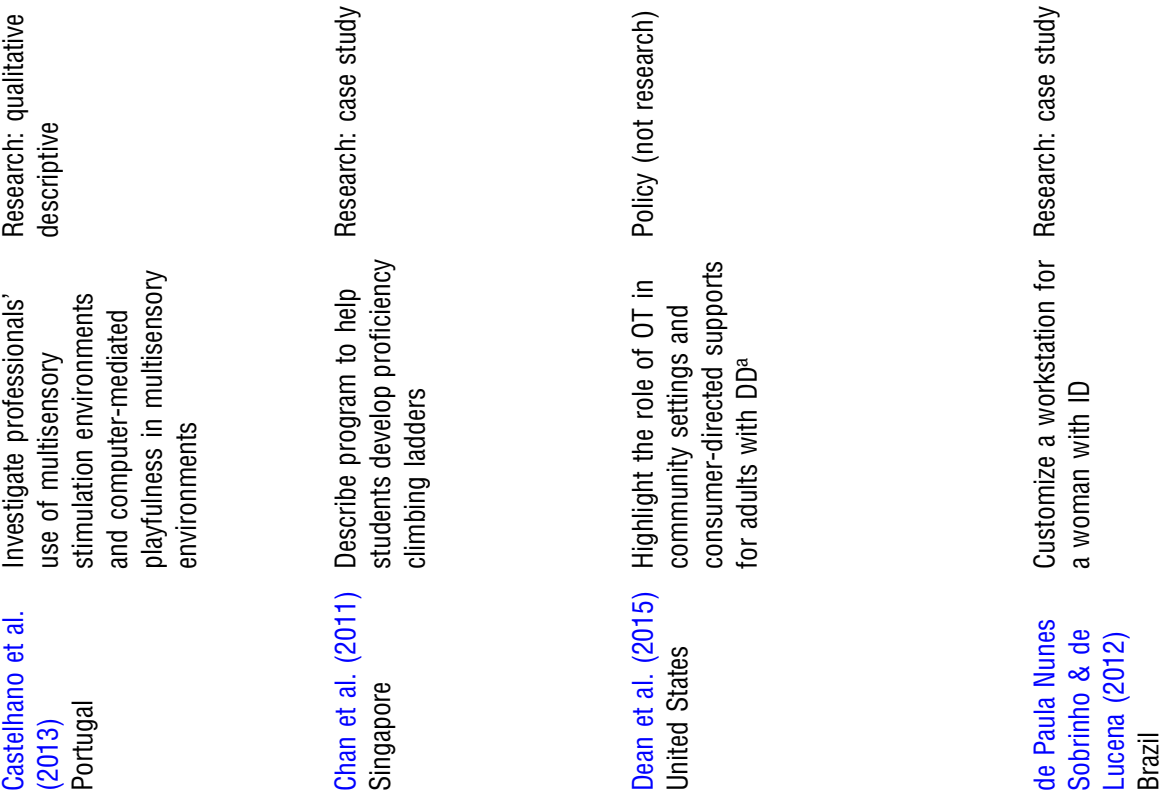

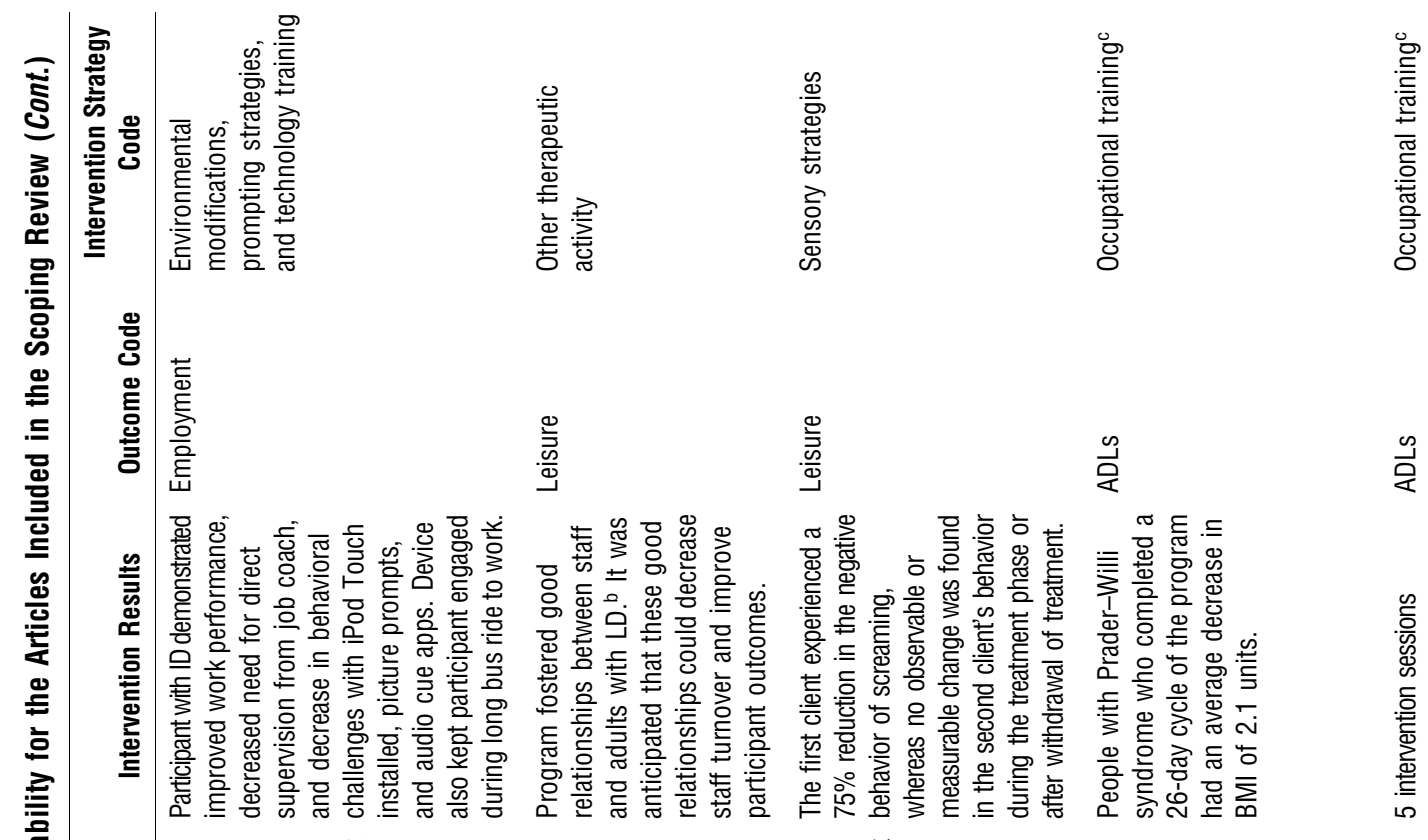

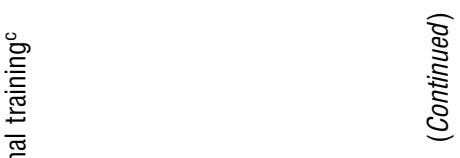

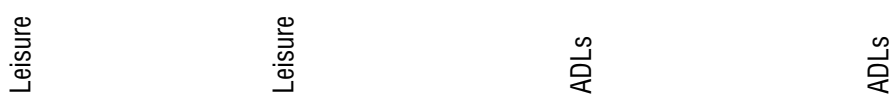

虽
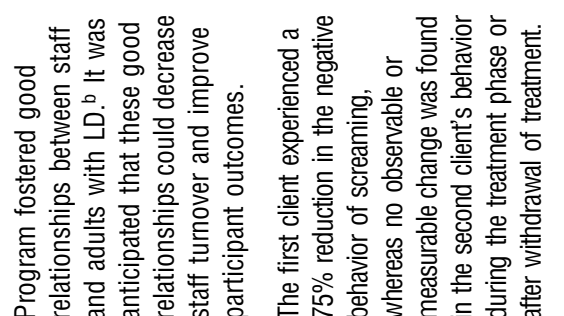

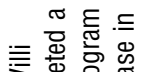

这 을 인

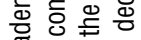

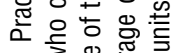

重 $\frac{0}{3} \frac{\pi}{0}$

응 츤 둥

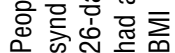
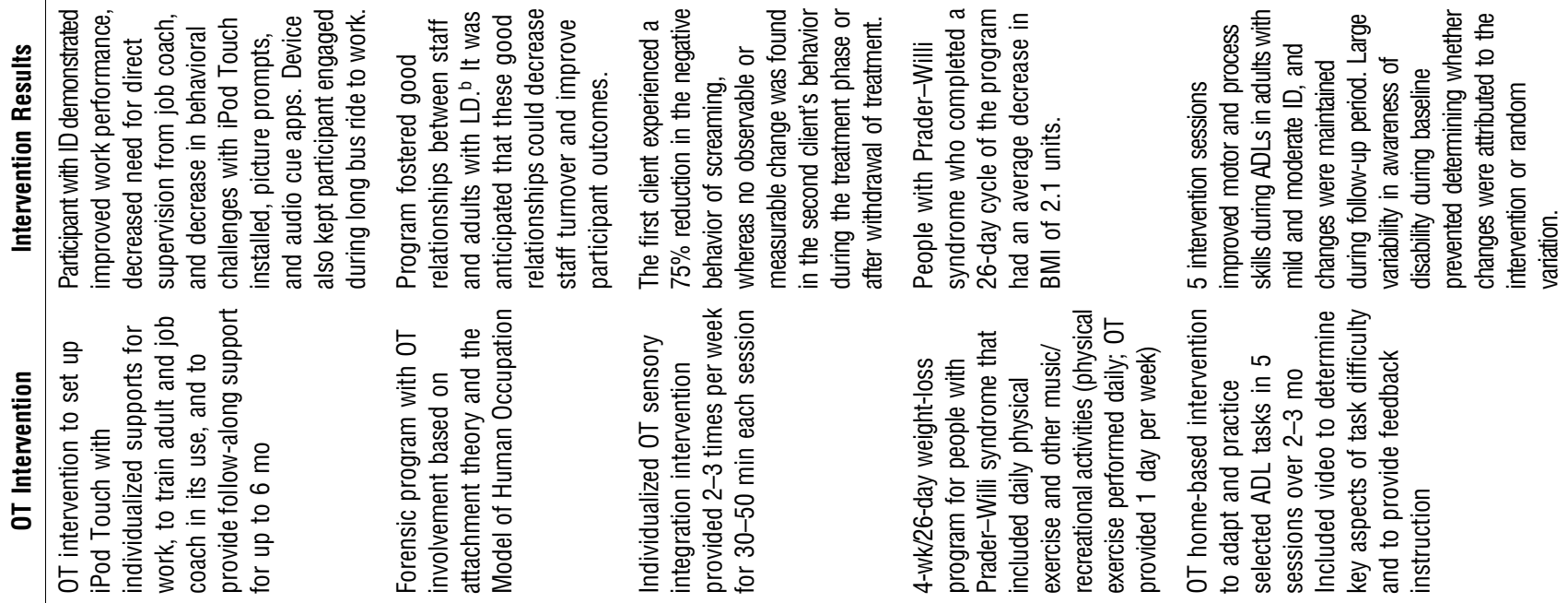

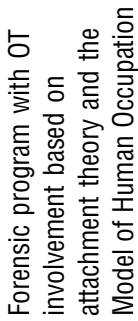

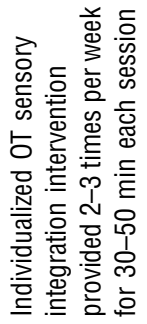

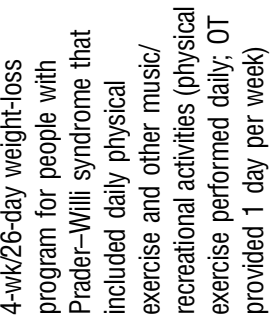

흘

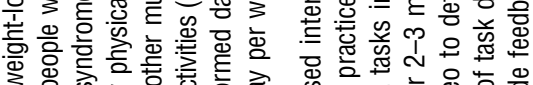

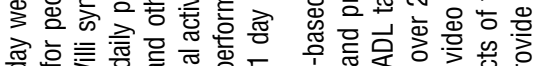

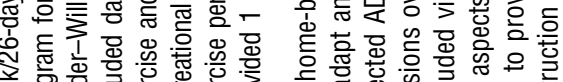

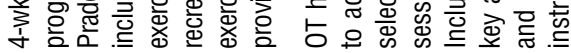

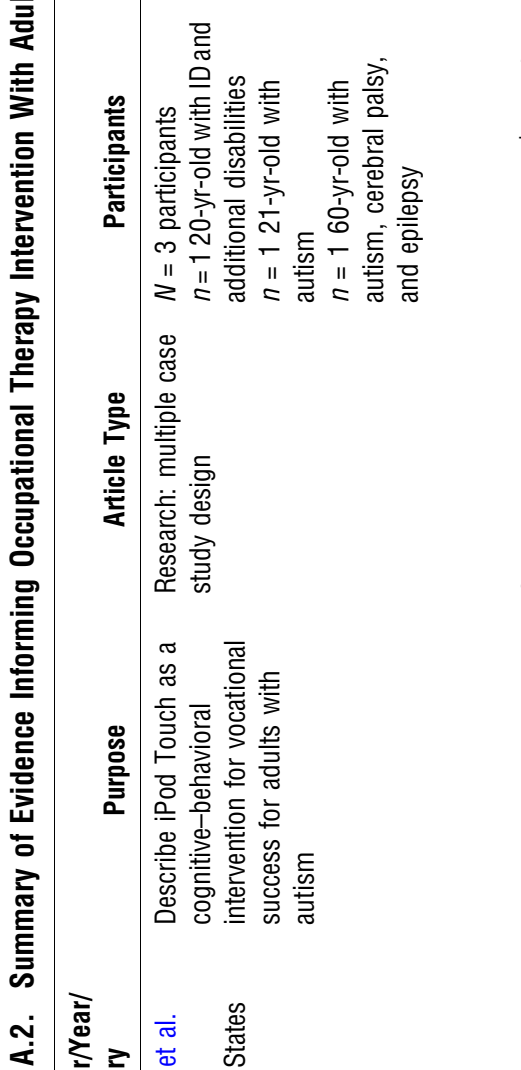

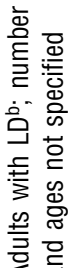

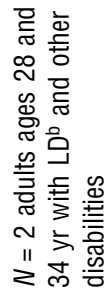

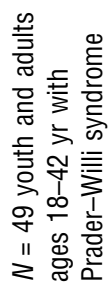

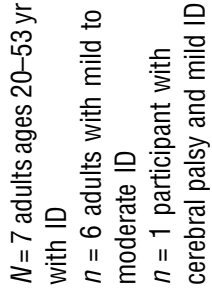

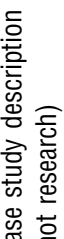

엉

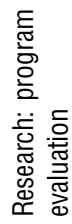

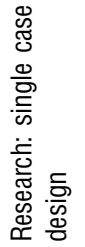

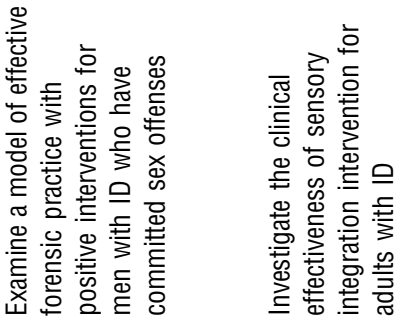

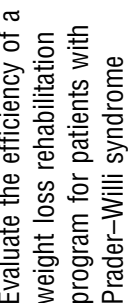

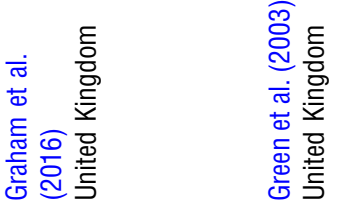

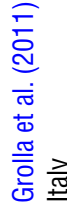

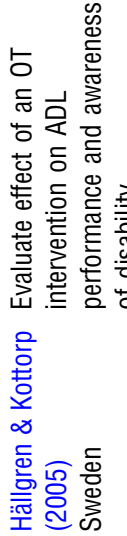



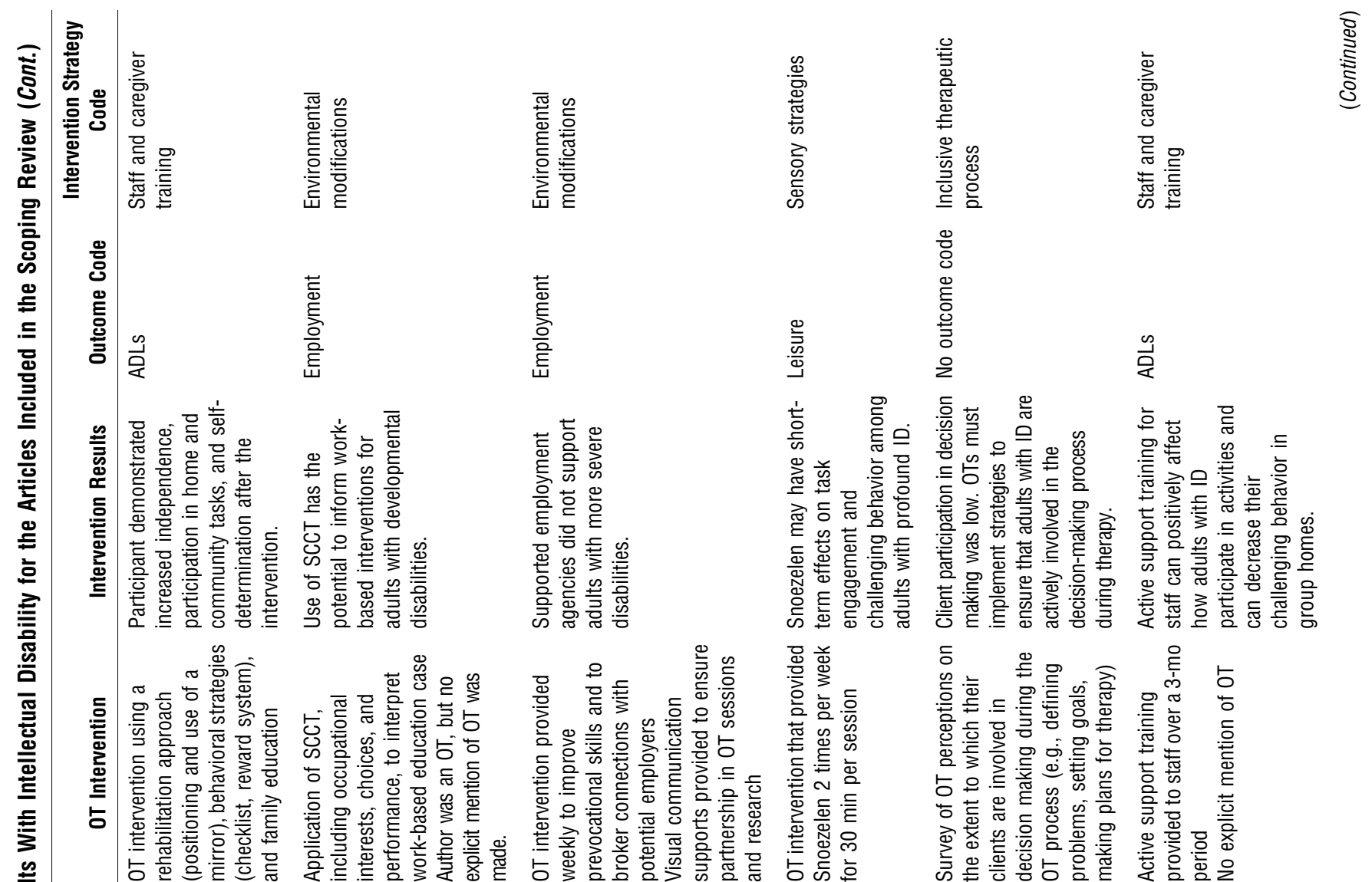

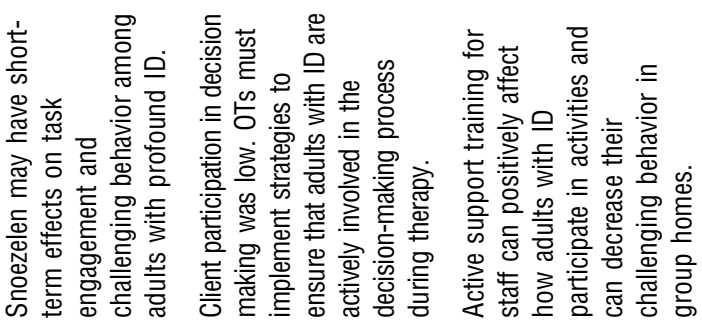

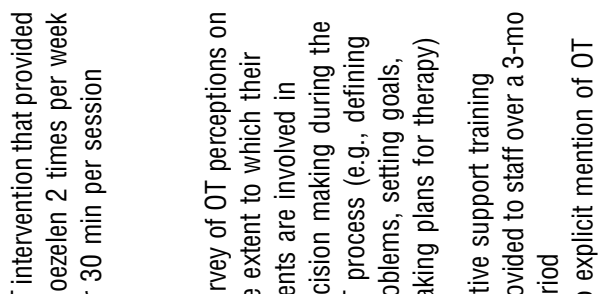

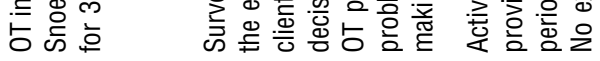
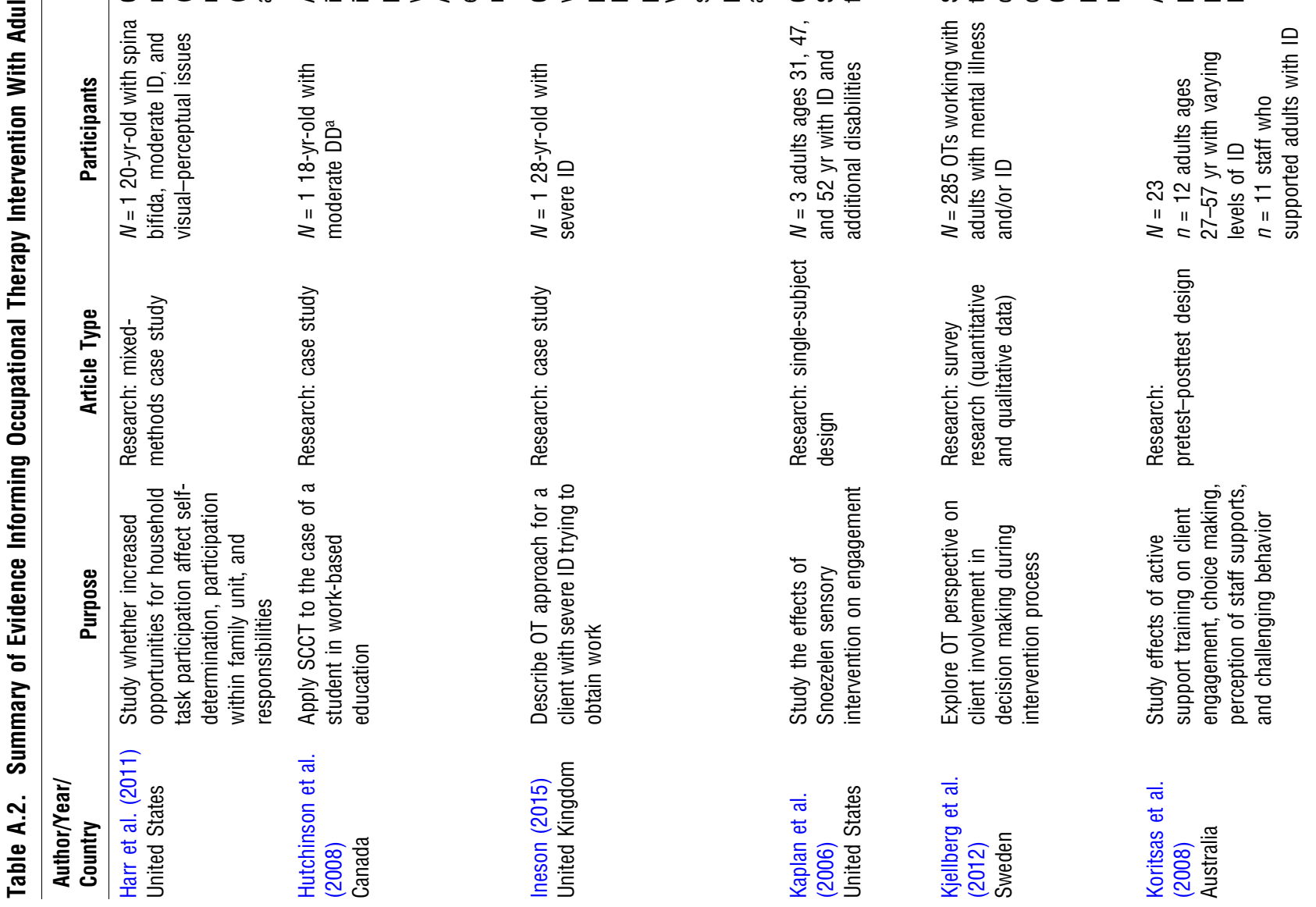

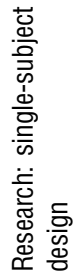

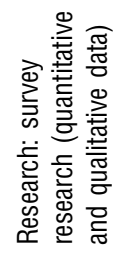

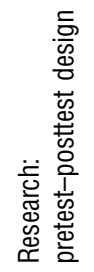

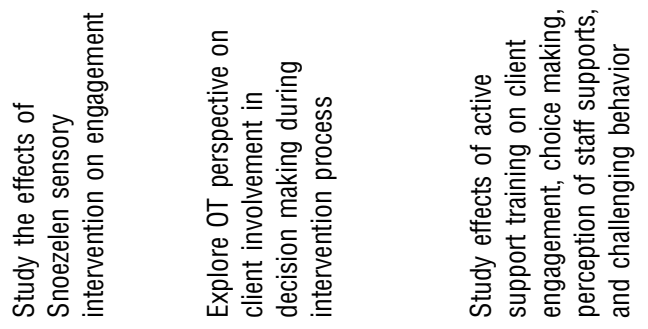

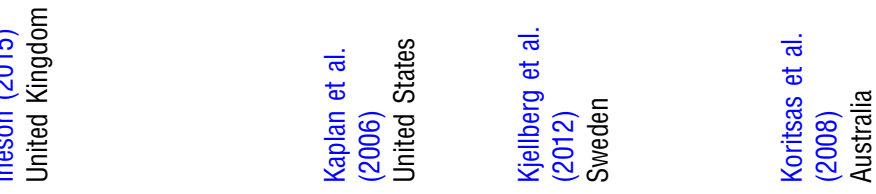




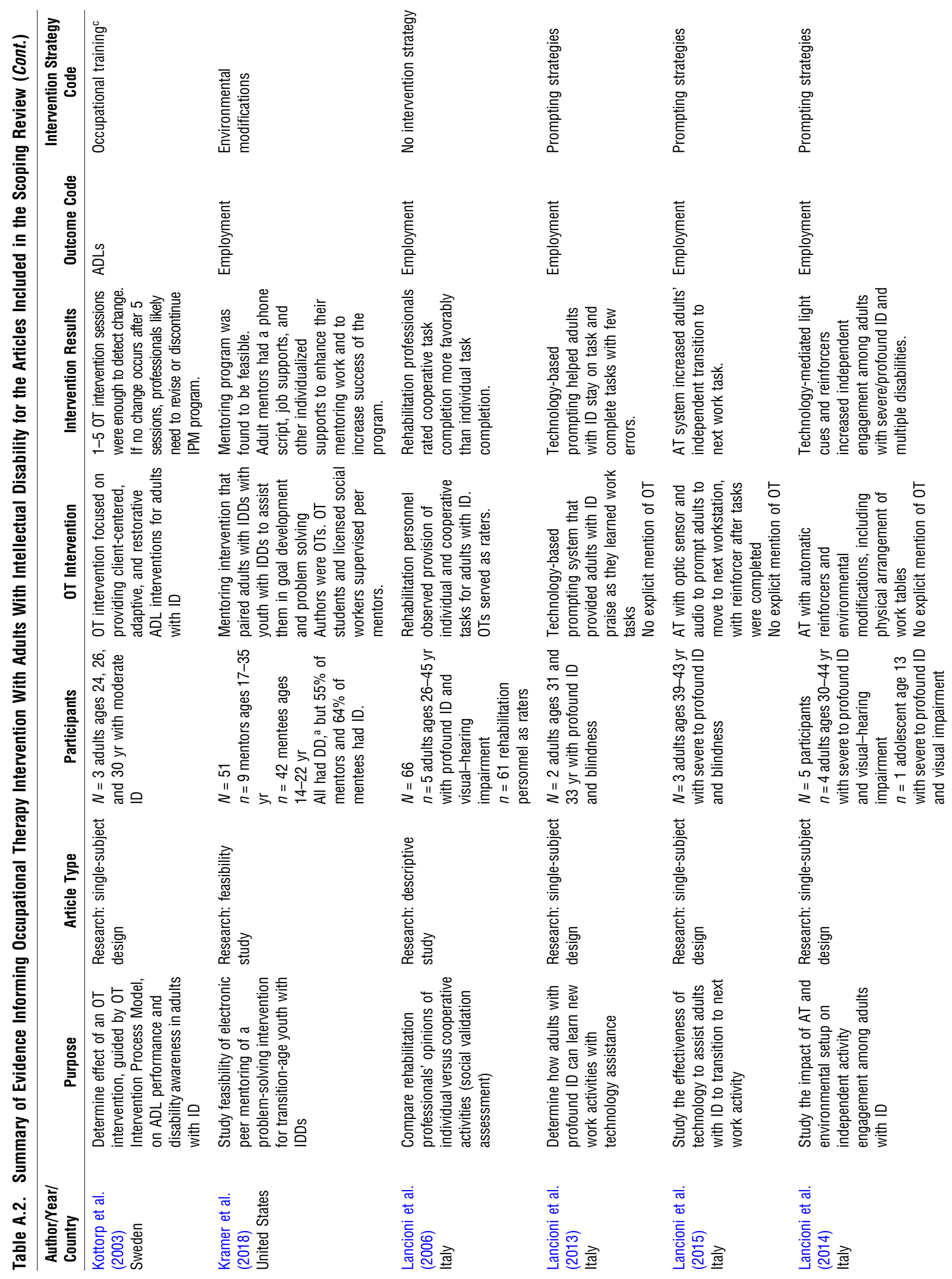



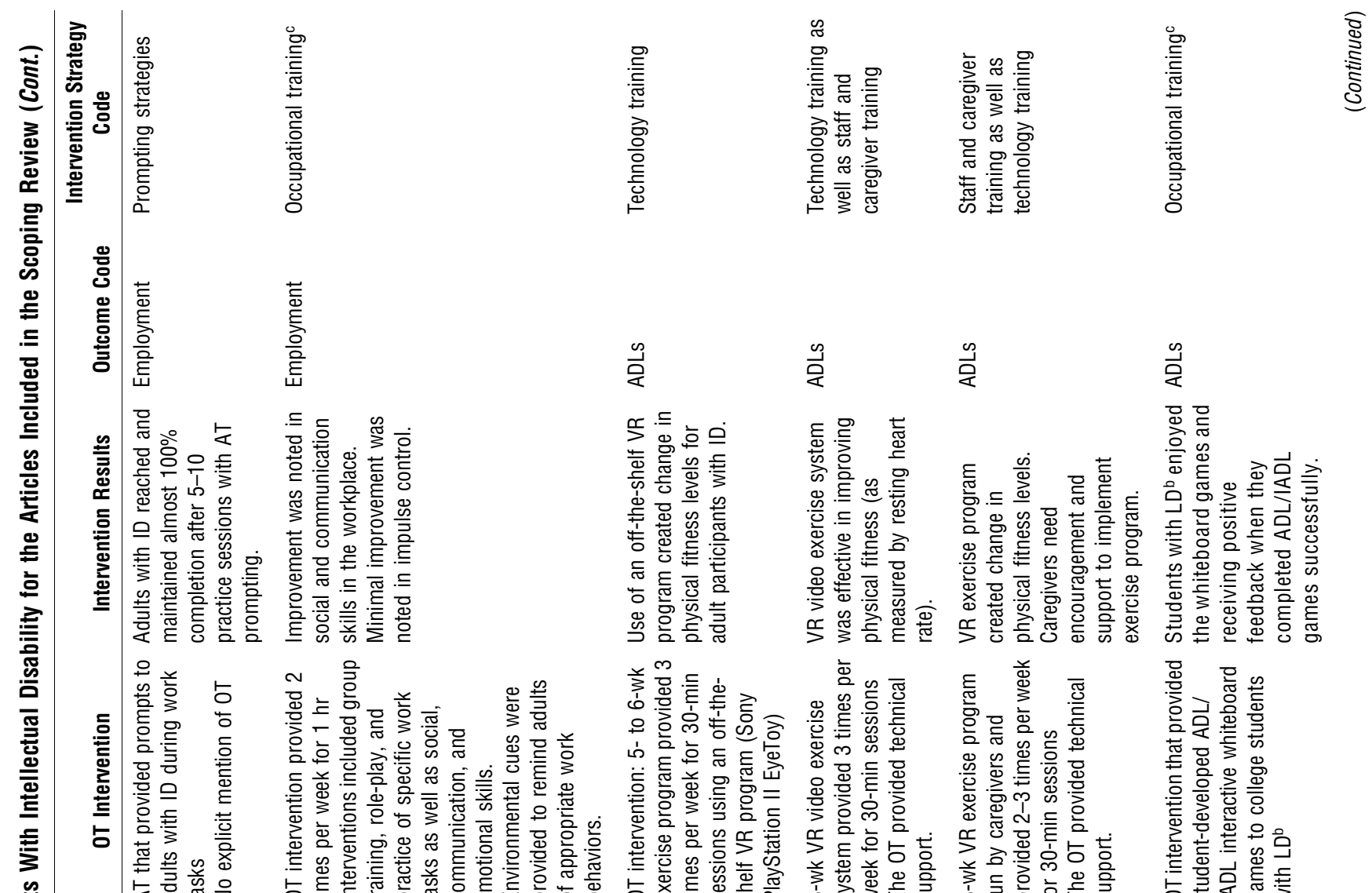

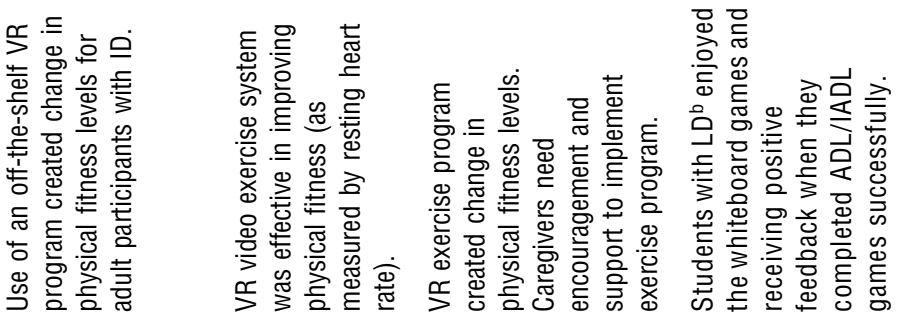

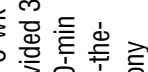

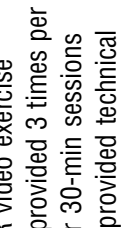

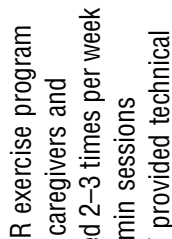

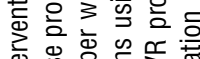

든흔

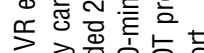

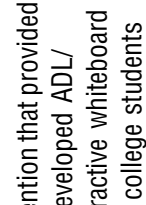

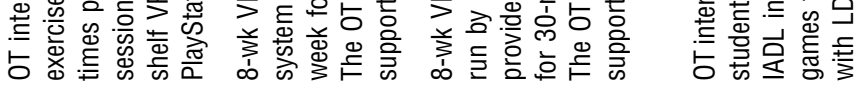

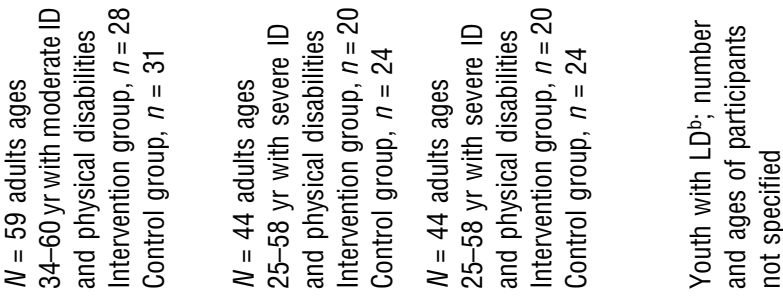

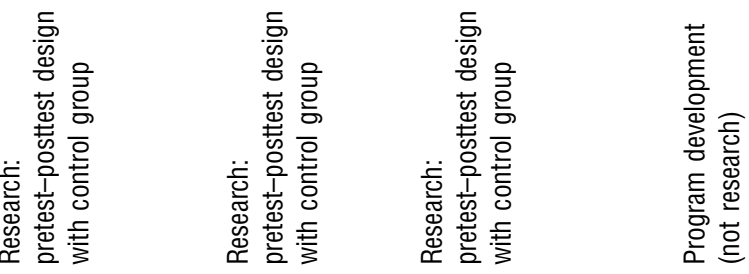

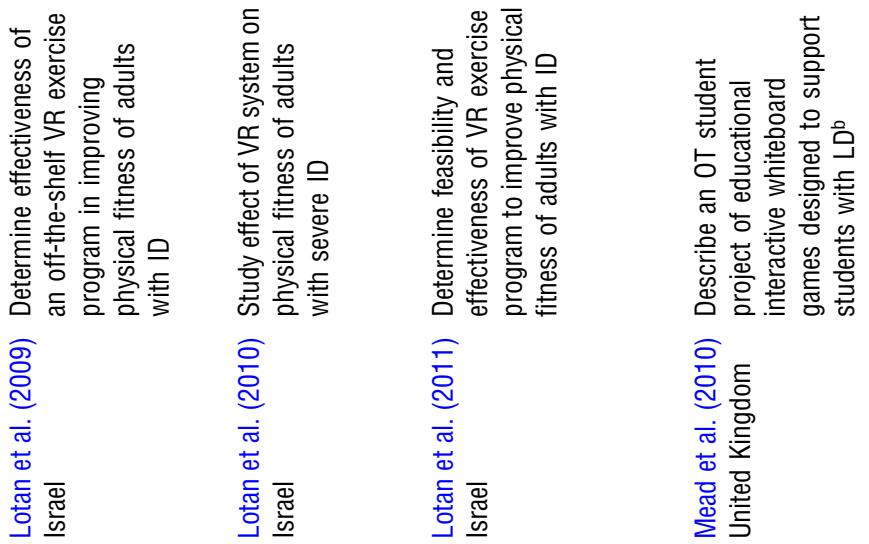




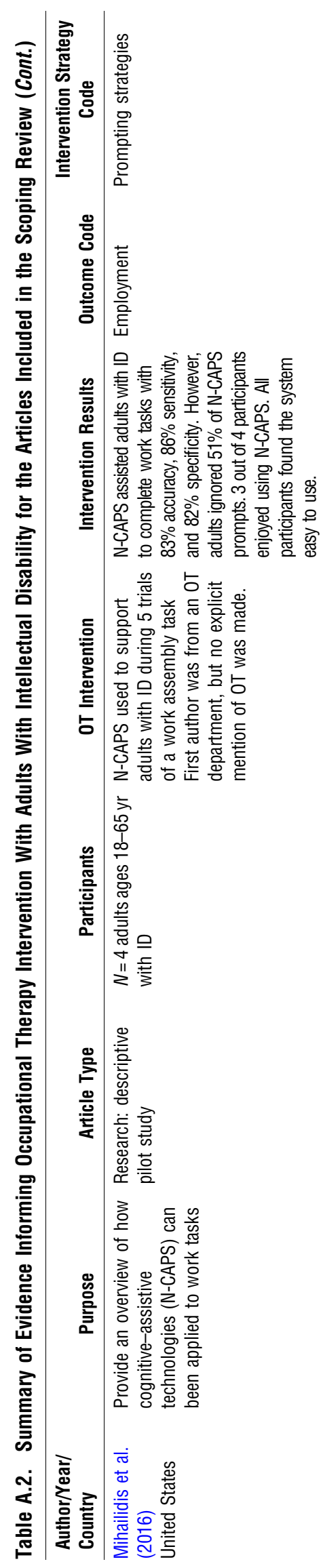

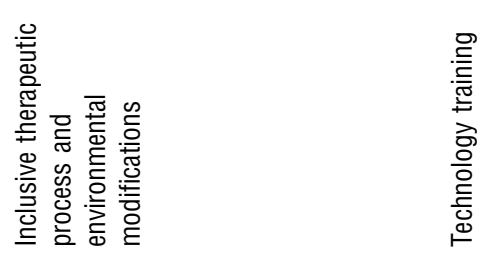

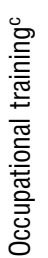

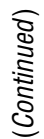

突

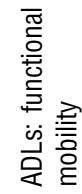

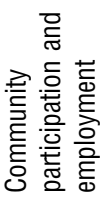

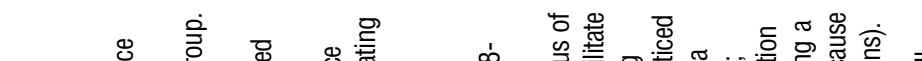

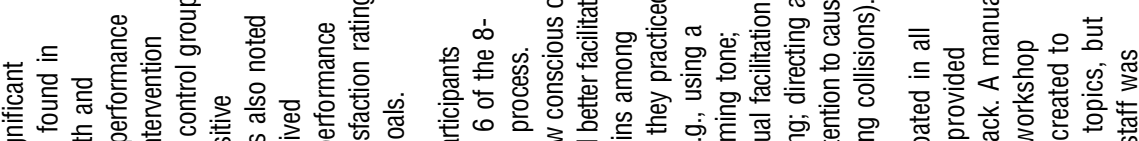

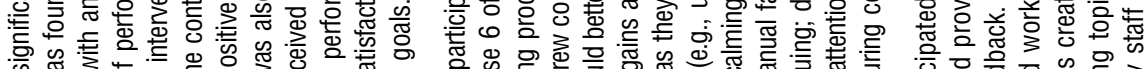

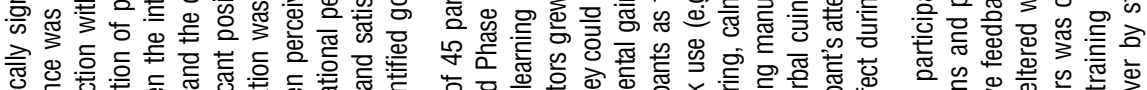

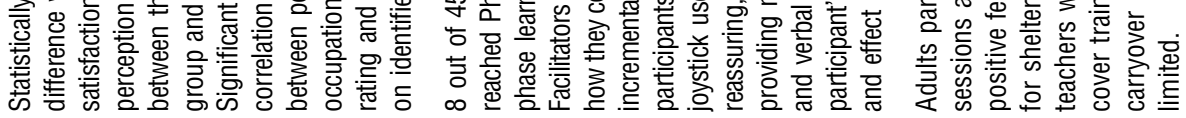

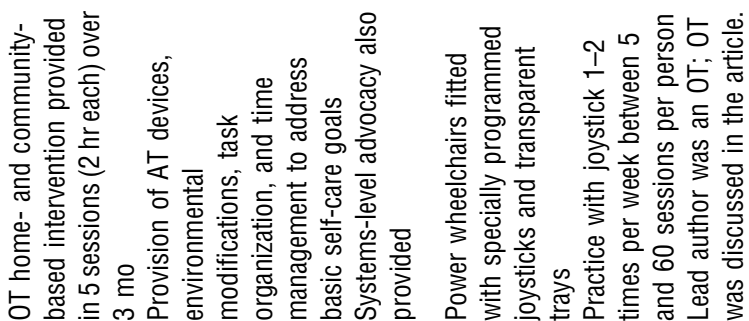

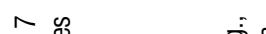

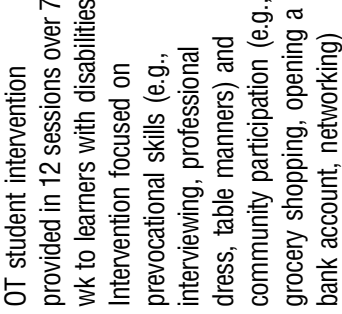

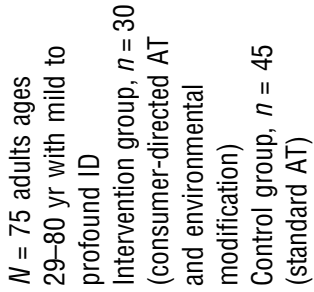

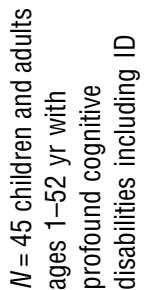

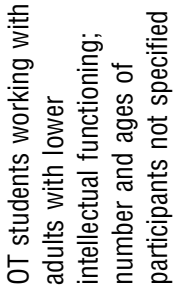

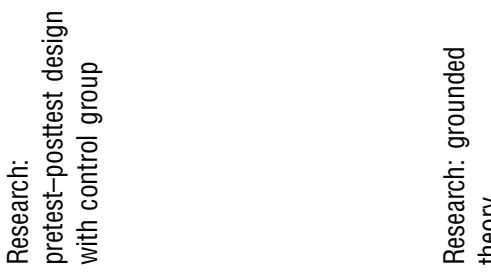

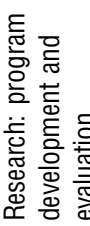
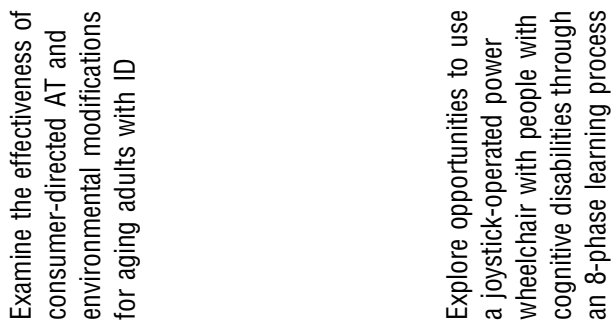

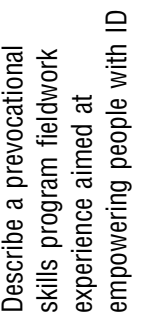
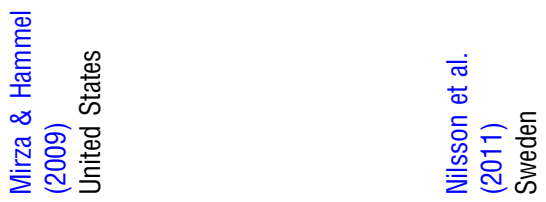

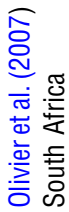



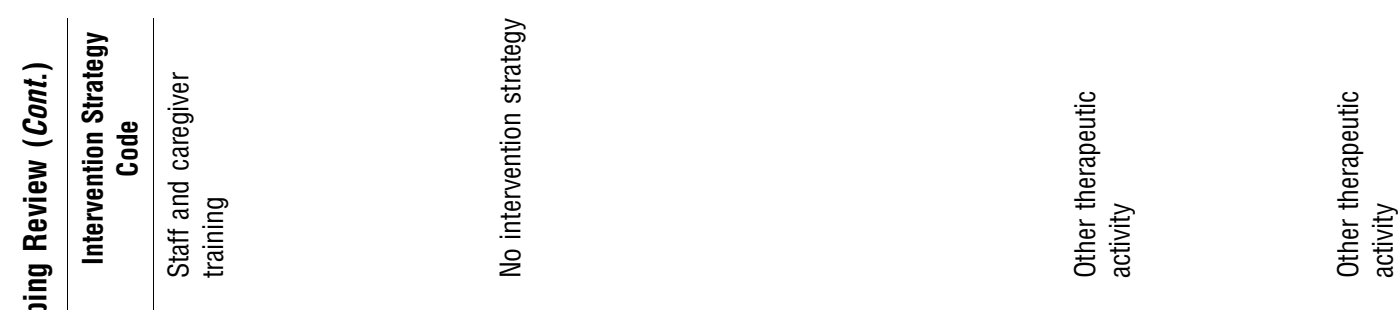

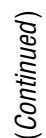

$\frac{\text { 응 }}{\circ}$
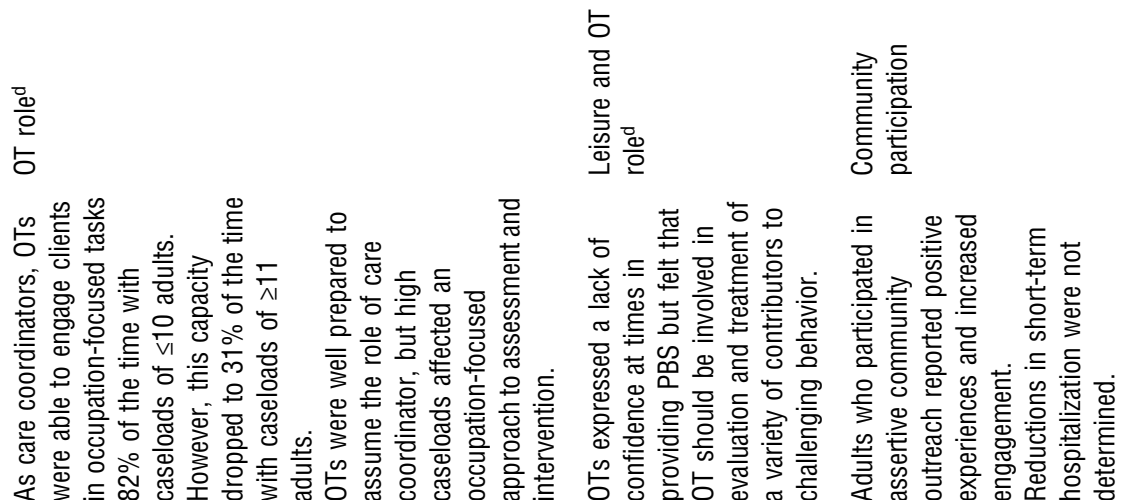

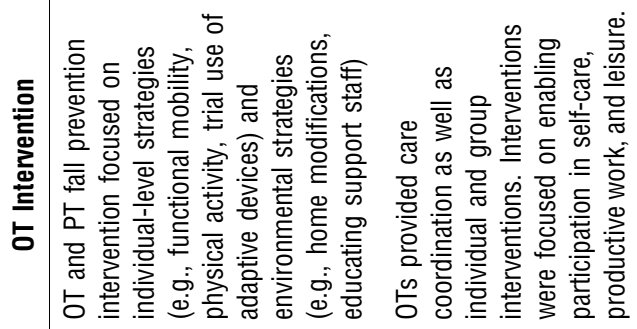

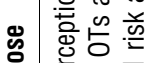

믛

흥ㅎㅎㅁ은

退

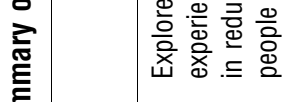

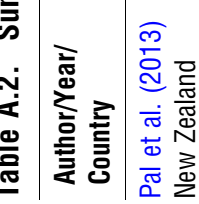

美

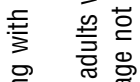

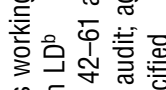

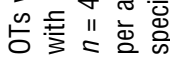

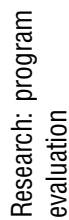

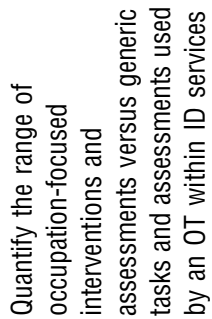

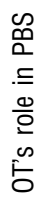

요 용

品

흥

흘 象

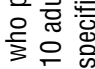

ら"

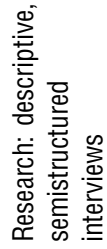

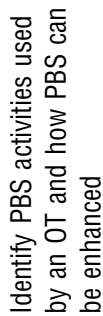

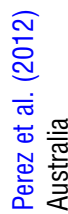

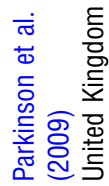

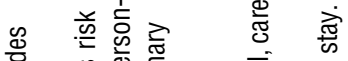

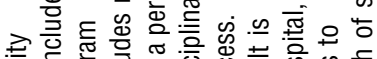

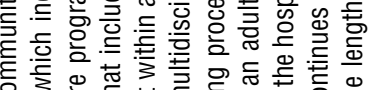

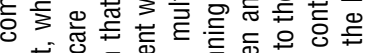

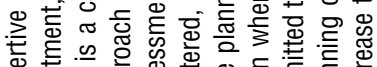

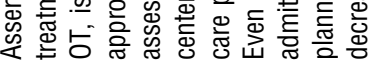

॥ 롫

幽

ㄴㅡㅡㅡㄹ

咅

空产

넝

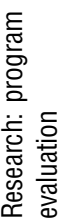

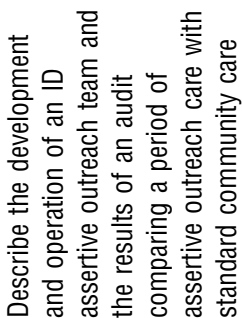

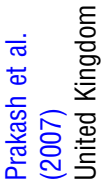




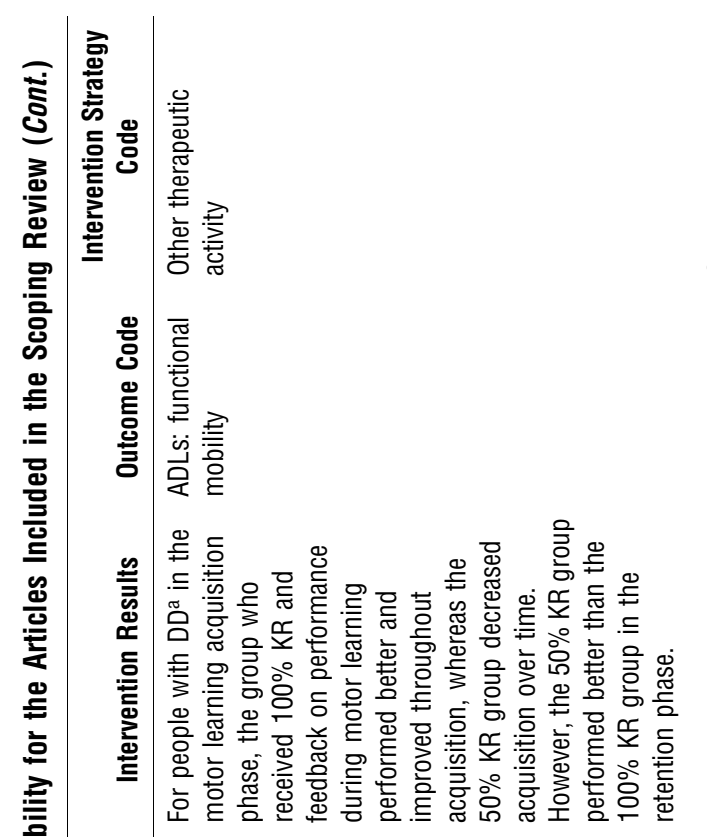

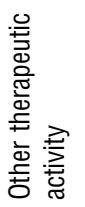

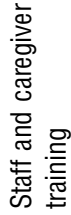

$\stackrel{\frac{0}{\leftrightarrows}}{\frac{0}{\omega}}$

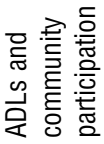

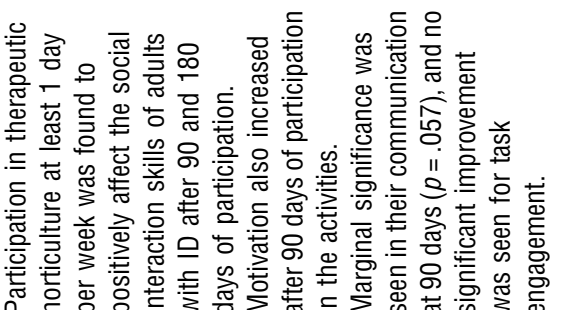

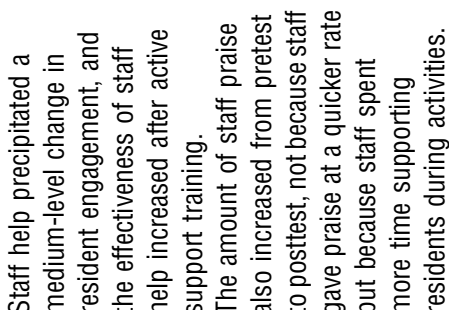

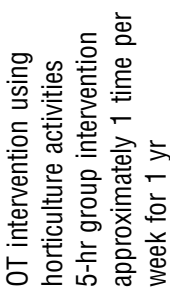

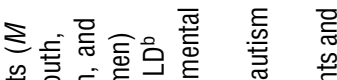

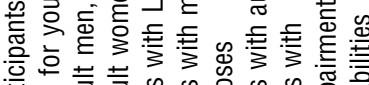

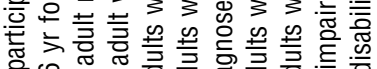

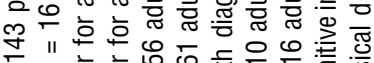

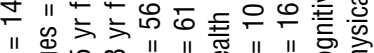

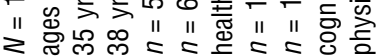
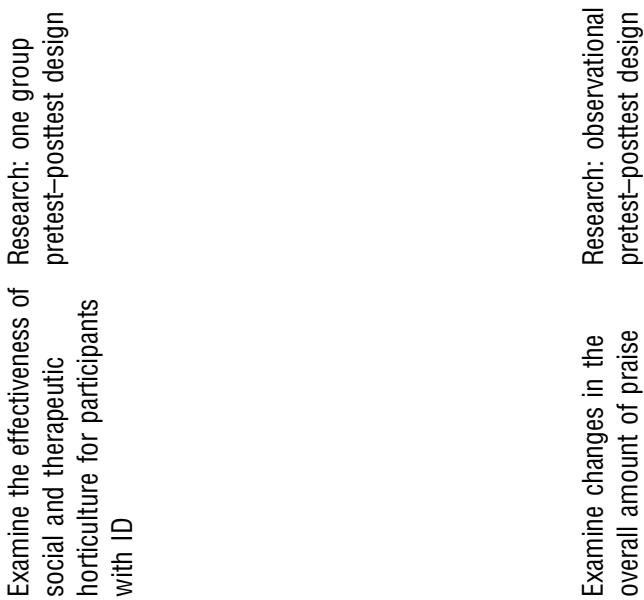

하음

言竞兽

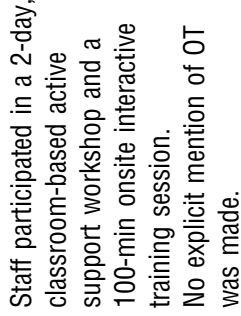

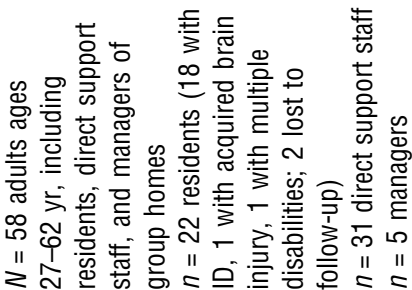

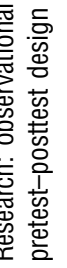

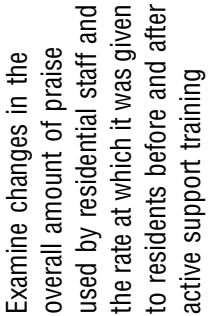

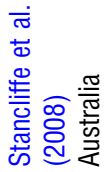




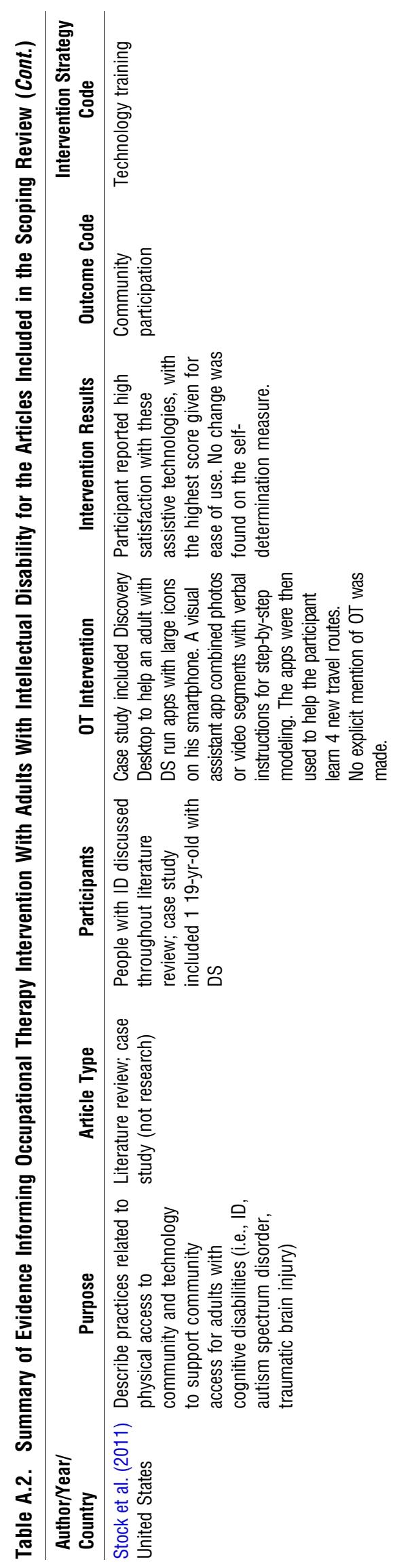

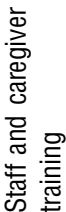

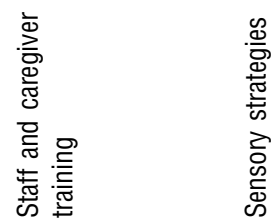



是

은

$\stackrel{\frac{0}{\leftrightarrows}}{\frac{0}{\omega}}$

完

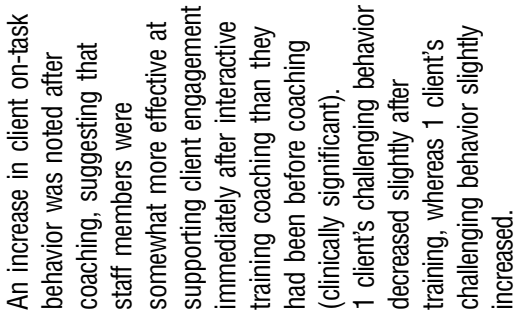

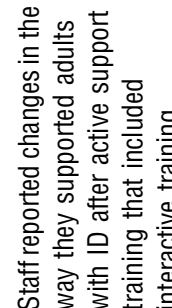

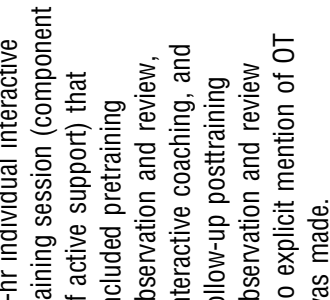

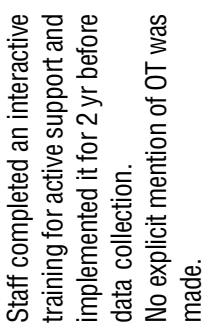

虽

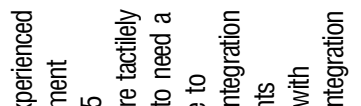

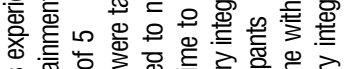

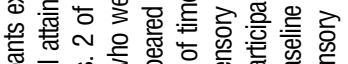

产宁

壳

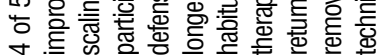

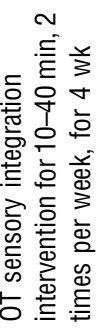

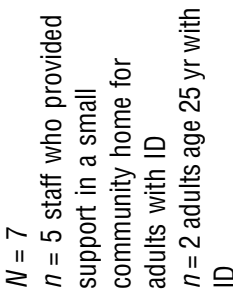

흉 흑

ำ

흔 윻

운 융

원엉

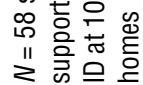

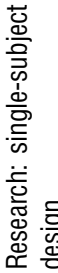
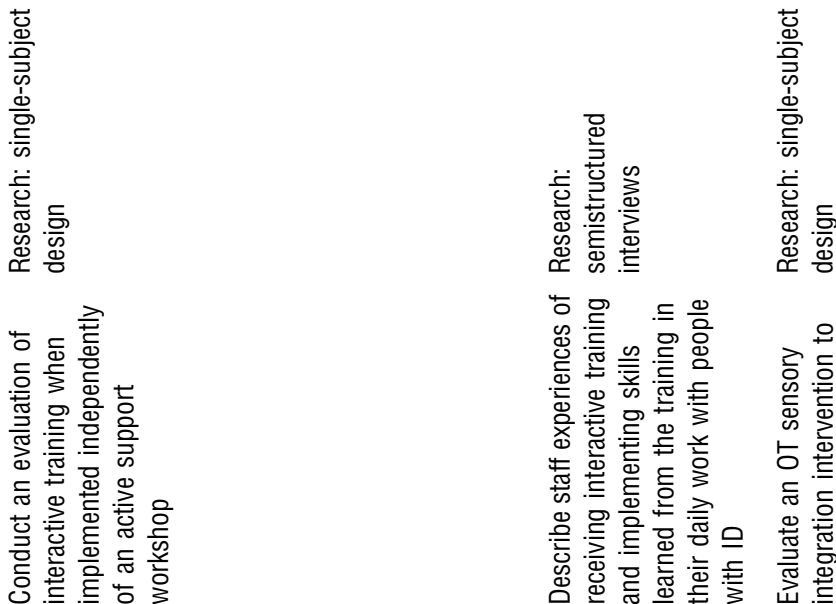

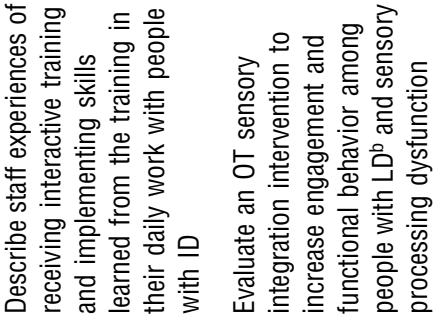

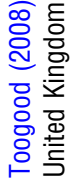

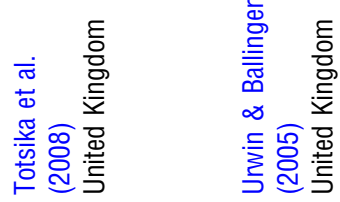



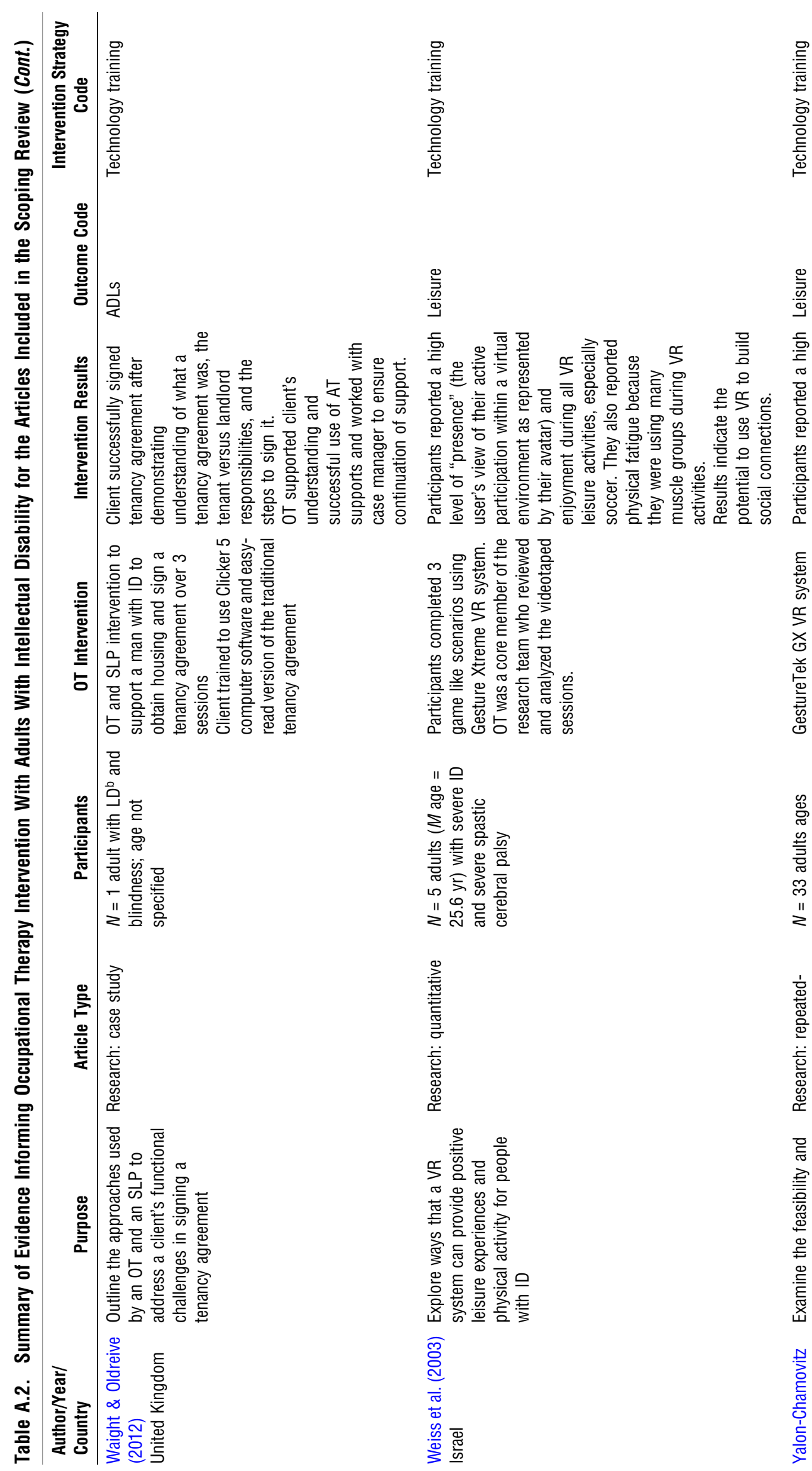

$\stackrel{\frac{0}{\leftrightarrows}}{\frac{\omega}{\leftrightarrows}}$

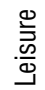

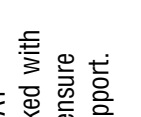

흠

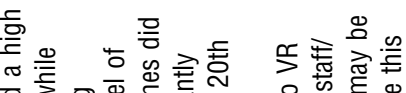

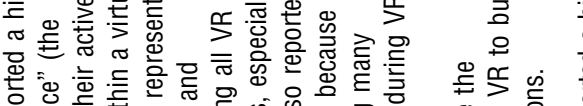

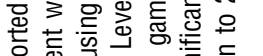

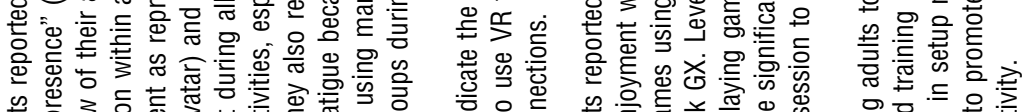

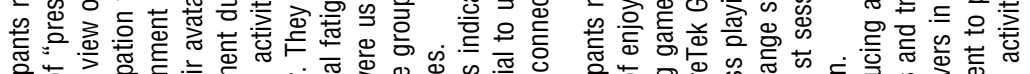

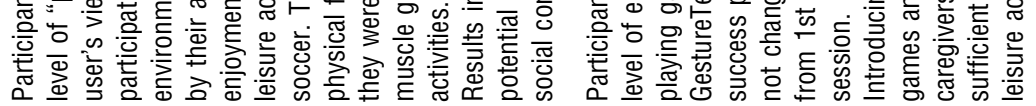

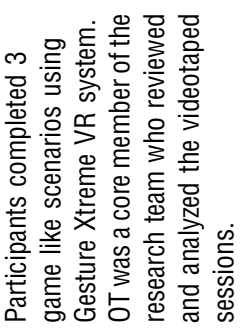

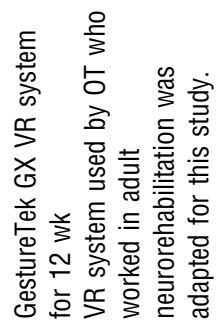

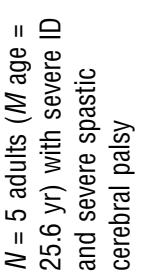

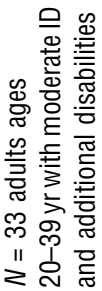

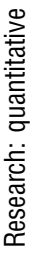
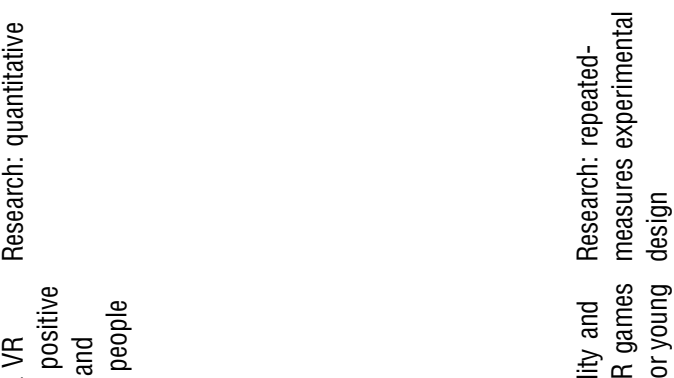

요유 은

華

分든 흫

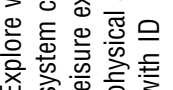

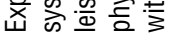

을 을으

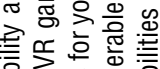

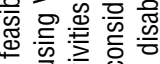

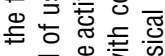

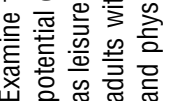

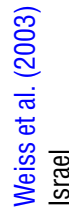

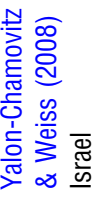




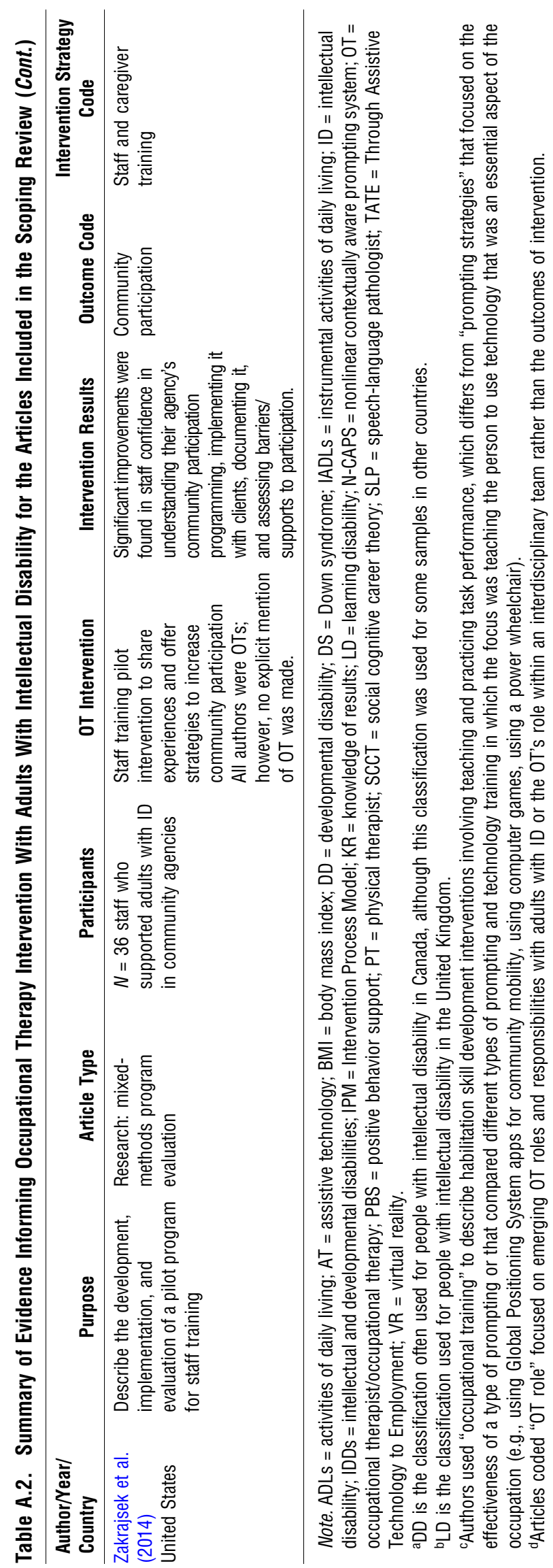

